\title{
DISCLAIMER
}

This report was prepared as an account of work sponsored by an agency of the United States Government. Neither the United States Govermment nor any agency thereol. nor any of their employes, makes any warranty, express or implied, or assumes any legal liability or responsibility for the accuracy, completeness, or usefulness of any information, apparatus, product, or process disclosed, or represents that its use would not infringe privately owned rights. Reference herein to any specific commercial product, process, of service by trade narte, trademark. manufacturer, os otherwise does not necessarily constilute or imply its endorsement. recom. mendation, or favoring by the United States Government or any agency therear. The views and opinions of athors expressed herein do not necessarily state or reflect those of the United States Goyemment or any agency thereol.

\section{Atomic Physics Studies of Highly Charged Ions on Tokamaks Using X-Ray Spectroscopy}

\author{
P. Beiersdorfer \\ University of California, Lawrence Livermore National \\ Laboratory \\ Livermore, California 94550, USA
}

\author{
S. von Goeler, M. Bitter, and K. W. Hill \\ Princeton University, Plasma Physics Laboratory. \\ Princeton, New Jersey 08543, USA
}

\begin{abstract}
An overview is given of atomic physics issues which have been studied on tokamaks with the help of high-resolution $x$-ray spectroscopy. The issues include the testing of model calculations predicting the excitation of line radiation, the determination of rate coefficients, and accurate atomic structure measurements. Recent research has focussed primarily on highly charged heliumlike ( $22 \leq Z \leq 28$ ) and neonlike ( $34 \leq Z \leq 63$ ) ions, and results are presented from measurements on the PLT and TFTR tokamaks. Many of the measurements have been aided by improved instrumental design and new measuring techniques. Remarkable agreement has been found between measurements and theory in most cases. However, in this review those areas are stressed where agreement is worst and where further investigations are needed.
\end{abstract}




\section{Introdution}

The spectroscopy of the $x$-ray line emission of highly charged ions plays a prominent role on present-day tokamaks. ${ }^{1-4}$ High-resolution $\mathrm{x}$-ray spectroscopy of highly charged ions provides crucial measurements of the ion temperature profile and the plasma rotation velocity. ${ }^{5-9}$ It is also used to measure the electron temperature profile, charge state distribution of impurity ions, transport phenomena, and the density profile of neutral hydrogen. ${ }^{10-15}$

The strong interest in the $x$-ray line emission of highly charged ions for plasma diagnostics has led to the development of precision spectroscopic instruments and is accompanied by the need to understand basic atomic physics issues. As a result, many important questions concerning the physics of highly charged ions have been investigated on tokamaks during the last decade following the development of high-resolution $x$-ray spectroscopy. Areas of investigation include precision atomic structure measurements, the testing of atomic physics models, and measurements of rate coefficients. Atomic physics investigations on tokamaks have been very fruitful because relevant parameters such as the electron temperature are accurately known from independent, nonspectroscopic measurements. Atomic physics models, therefore, can be tested under controlled conditions. The characteristics of tokamak plasmas are similar to those of solar flares. Hence analysis techniques developed for low-density, astrophysical plasmas ${ }^{16,17}$ can be applied to the study of highly charged ions in tokamaks. Atomic physics research on tokamaks is also aided by the capability to seed the plasma at precisely selected moments with any element of choice using fast gas valves or laser ablation..$^{18,19}$ Moreoever, the recent attainment of high electron temperatures has allowed the production and observation of very highly charged ions with net charges up to $53+$.

In the following we discuss some of the aspects of the physics of highly rharged ions which have been investigated with the help of high-resolution $\mathrm{x}$-ray spectroscopy on tokamaks. We review new techniques and present recent measurements of highly charged heliumlike and neonlike ions from 
the Princeton Large Torus (PLT) and the Tokamak Fusion Test Reactor (TFTR). We have given special attention to issues which are unresolved and which require further investigations before satisfactory agreement with theory is obtained.

The paper is organized as follows. In the next section a brief review of tokamaks, plasma parameters, and instrumentation used in x-ray spectroscopy is given. Recent investigations of the excitation mechanisms of heliumlike and neonlike ions are discussed in Section 3, and efforts are outlined which attempt to reconcile the measurements with atomic physics models. In Section 4 we focus on rate measurements. In Section 5 recent contributions to the atomic structure theory of highly charged ions are presented. In the concluding section we briefly outline areas of measurement which have not been considered but which are relevant for future studies.

\section{Experimental Conditions}

The plasmas in tokamak discharges are typically well diagnosed. A large assortment of plasma diagnostics measures such quantities as plasm? current, magnetic oscillations, and density fuctuations. ${ }^{20}$ Most important for atomic physics measurements are accurate determinations of the election temperature and density. These measurements are reliably provided by laser scattering, microwave interferometry, $x$-ray pulse height spectrometry, and electron cyclotron emission. ${ }^{20}$

Typical electron temperature and electron density profiles obtained with laser scattering on PLT are shown in Fig. 1. During ohmic heating the peak electron temperature in the center of PLT reaches $1-3 \mathrm{keV}$ depending on plasma current, magnetic field, and electron density. ${ }^{21}$ The electron temperature can be increased considerably with auxiliary electron heating. In PLT peak temperatures in excess of $6 \mathrm{keV}$ were attained with the addition of a modest amount of lower-hybrid wave heating. ${ }^{22,23}$ An electron temperature profile measured under such conditions is shown in Fig. 1. The line-averaged density is $1 \times 10^{13} \mathrm{~cm}^{-3}$. The corresponding ion temperature ranges from 0.5 
to $1.0 \mathrm{keV}$. Hence the broadening of a given $x$-ray line due to the Doppler effect ranges from $\lambda / \Delta \lambda \approx 3000-8000$ for elements below $Z=50$. Electron temperatures equal to or exceeding those on PLT have recently been achieved on TFTR. However, here high electron temperatures are attained as a by-product of ion heating. (Electron temperatures up to $8.5 \mathrm{keV}$ and ion temperatures between 20 and $30 \mathrm{keV}$ have been measured on TFTR in the so-called supershot regime. ${ }^{7-9,24}$ ) As a result, Doppler broadening of the $x$-ray lines increases significantly and can hamper the study of closely spaced lines because of overlap.

The attainment of high electron temperatures in tokamaks has allowed the production of very high jonization stages. In PLT we have been able to measure the x-ray transitions of neonlike europium $\left(\mathrm{Eu}^{53+}\right) \cdot{ }^{25}$ In Fig. 2 we have plotted the minimum central electron temperature which was necessary to detect $n=3 \rightarrow 2 x$-ray line emission from an ion in the neonlike charge state on PLT with a bent-crystal spectrometer. The figure implies that it will be possible to observe neonlike ytterbium $(Z=70)$ in plasmas with electron temperatures $\geq 10 \mathrm{keV}$. Such temperatures are presently within the range of TFTR and JET, and may be achieved in smaller tokamaks such as ASDEX, DIII-D, T-10, or PLT by means of lower-hybrid or electron cyclotronresonance heating. ${ }^{26}$ At these temperatures we can also expect emission from heliumlike ions with $Z \approx 50$ or nickel-like ions with $Z \geq 92$.

Figuse 1 shows that the electron temperature varies from several $\mathrm{keV}$ in the center to a few $\mathrm{eV}$ at the edge of the plasma. As a result, the plasma contains shells of ions whose charge states are decreasing from the inside out. This effect is illustrated in Fig. 3(a). The figure shows the charge state distribution of selenium calculated assuming coronal equilibrium for the temperature profile indicated. However, the radial ionization balance is not solely determined by ionization and recombination, as assumed in coronal equilibrium, but it is affected by ion transport, i.e., by radial ion motion and diffusion. The effect of including plasma transport in the ionization balance is shown in Fig. 3(b). Transport tends to broaden the spatial range (and thus the range in electron temperature) where a particular charge state is 
located so that recombination can take place in colder plasma regions, and ionization in hotter regions, where the rates are higher in both cases, than without transport. ${ }^{27}$

While the mechanisms leading to transport of electrons and ions in tokamak plasmas are still poorly understood, there is a large body of measurements of the transport parameters, ${ }^{28-33}$ so that the effect of transport on atomic processes can be adequately estimated from phenomenological transport models. Indeed, the profiles in Fig. 3(b) which have been calculated with a measured diffusion coefficient are in good accord with measured profiles of fluorinelike, neonlike, and sodiumlike selenium as shown in Ref. 15. Transport models could actually be improved, if atomic physics parameters, in particular ionization and recombination rate coefficients, were known with more certainty.

The instrumentation used to measure high-resolution $x$-ray spectra on tokamaks typically consists of bent-crystal spectrometers of the Johann ${ }^{10,34-30}$ or von Hámos ${ }^{13,40}$ type. Position-sensitive single- or multi-wire proportional counters are used for photon detection. The resolving power of these instruments typically equals or exceeds the $x$-ray line width due to Doppler broadening. Most crystal spectrometers operate in a low vacuum or helium atmosphere to avoid absorption by air and measure $\mathrm{x}$ rays below $5 \AA$. On PLT and TFTR we have used Johann-type bent-crystal spectrometers to measure high-resolution $x$-ray spectra of heliumlike ions in the range $18 \leq$ $\mathrm{Z} \leq 28$ and neonlike jons in the range $47 \leq \mathrm{Z} \leq 63$. A new high-resolution ultra-soft $x$-ray (USX) spectrometer has been developed for use on PLT to study the wavelength region from $4-25 \AA .{ }^{15}$ The ultra-soft wavelength region was not accessible before with existing high-resolution spectrometers. The USX spectrometer uses a bent crystal in the Johann geometry, as other high-resolution spectrometers. However, the instrument uses a microchannel plate-intensified photodiode array for photon detection and operates in vacuo. The new instrument also has fast time resolution ( $4 \mathrm{msec}$ per spectrum) and can scan the minor radius of the plasma. Examples of its use will be presented in Sections 3 and 4. 


\section{Study of the Excitation Processes}

$\mathrm{X}$-ray line emission can provide valuable information on the plasma which contains the emitting ions. For some plasmas such as laser-produced or astrophysical plasmas spectroscopy often is the only tool which gives access to the plasma properties. Helce a thorough understanding of the mechanisms which lead to $\mathrm{x}$-ray line emission are paramount to the use of $\mathrm{x}$-ray spectra for diagnostic purposes. Since the properties of tokamak plasmas are well known, $x$-ray line emission from tokamak plasmas can be used to perform careful tests of the atomic physics models used to interpret $\mathrm{x}$-ray spectra.

In the next section we first discuss efforts to interpret $x$-ray spectra from heliumlike ions. Subsequently, we present new results on comparing tokamak spectra of neonlike ions with atomic models. In both cases considerable discrepancies between observations and model calculations are noted for specific transitions.

\subsection{Heliumlike Ions}

The $\mathrm{x}$-ray spectra of highly charged heliumlike ions are the most studied on tokamaks. This is largely due to the stimulus provided by observations of similar spectra from the sun and by the concurrent development of a large theoretical database. ${ }^{16,17} \mathrm{X}$-ray spectra from heliumlike ions also have been exploited in fusion research for their great plasma diagnostics potential. ${ }^{1}$ As a result of this interest, heliumlike spectra have now been observed in tokamaks from essentially all elements up to zinc $(Z=28) .^{41}$

Satellite spectra of heliumlike ions are understood the best. Extensive modelling efforts have shown that the satellite spectra can be explained by the two processes of dielectronic recombination and innershell excitation. ${ }^{42-46}$ In Fig. 4 the $n=2 \rightarrow 1$ spectrum of heliumlike titanium ( $Z=22)$ measured on TFTR is shown together with a synthetic spectrum computed from recent theoretical predictions. ${ }^{44,47}$ As seen from the figure, data and the synthetic satellite spectrum are in excellent agreement. 
The good agreement between data and thecry for the satellite lines, however, does not carry over to the heliumlike lines, i.e., the resonance line $w$, the intercombination lines $x$ and $y$, and the forbidden line $z$ (using the notation of Gabriel ${ }^{\mathrm{t} 6}$ to denote transitions from the levels ${ }^{1} P_{1},{ }^{3} P_{2},{ }^{3} P_{1}$, and ${ }^{3} S_{1}$, respectively). In Fig. 5 the observed line ratios $x / w, y / w$, and $z / w$ are plotted as a function of eleciron temperature. The figure demonstrates that the theoretical calculations which include direct excitation, resonances, and radiative cascade contributions from levels $n \geq 2$ adequately describe the data only at high electron temperature $T_{e} \geq 1.2 \mathrm{keV}$. At low temperature the discrepancies are as large as one order of magnitude. These results cannot be explained by recombination from hydrogenic titanium, which was left out in the calculations, because the line ratios are observed in the early phases of the discharge when the temperature is too low to ionize heliumlike ions in substantial amotints. On the other hand, the relative intensities of lines $x, y$, and $z$ appear to be related to the abundance of lithiumlike ions. ${ }^{44}$ This intimates that innershell ionization of lithiumlike ions may be the cause for the discrepancy with theory at low temperature. Innershell ionization, however, would only enhance line $z$. The enhancement of line ratio $z / w$ is 0.1 at $T_{e}=$ $0.6 \mathrm{keV}$ and 0.03 at $2 \mathrm{keV}$ for the measured abundance of jithiumlike ions. This enhancement is much too small to account for the observed discrepancies. Also, it cannot account for the anomalously large intensity of lines $x$ and $y$. Other processes ${ }^{44,48,49}$ have been proposed which could, in principle, populate the triplet states, but so far none can explain the discrepancies given the conditions of the experiment.

While most observations of $x$-ray spectra of heliumlike ions have been made from Maxwellian plasmas, some $\mathrm{cbservations} \mathrm{have} \mathrm{been} \mathrm{made} \mathrm{in} \mathrm{plas-}$ mas which have a non-thermal component. ${ }^{50-53}$ In measurements of the $x$-ray spectrum of heliumlike titanium on the Doublet III tokamak during electron cyclotron heating an anomalously low intensity of line $z$ was observed..$^{52,53}$ The ratio $R=z /(x+y)$ was measured in the density range $2 \times 10^{13}$ $1.5 \times 10^{14} \mathrm{~cm}^{-3}$ and found to decrease with increasing density. According to theoretical predictions $R$ should not be density-sensitive for densities be- 
low $10^{15} \mathrm{~cm}^{-3}$. At the highest density $R$ was an order of magnitude smaller than predicted. Similar to the large discrepancies with theory observed in Maxwellian plasmas, the anomalously low intensity of line $z$ observed in nonMaxwellian plasmas challenges basic atomic physics to provide a satisfactory explanation.

Poor agreement between theoretical models which predict the relative line intensities of the heliumlike lines and measurements has also been noted for cases where radiative recombination of hydrogenic ions is a significant mechanism for the population of excited levels in heliumlike ions. ${ }^{8,54.55}$ In Fig. 6 we show two spectra of heliumlike iron which we have measured recently on TFTR. The spectrum in (a) has been recorded from the plasma center where recombination from $\mathrm{Fe}^{25+}$ is negligible; the spectrum in (b) was measured from a non-central region where recombination plays an important role because of rapid transport of hydrogenic iron from the center to cooler plasma regions. The spectra have been fitted to synthetic spectra using least squares. Good accord between data and calculations is found. However, the fit in Fig. 6(b) requires a substantially higher recombination rate coefficient than provided by theory. Further investigations are in progess.

The effect of recombination on the $n=2 \rightarrow 1$ spectrum of heliumlike argon has also been studied in the Alcator $\mathrm{C}$ tokamak, ${ }^{54,55}$ and a rate coefficient five times larger than predicted was necessary to obtain quantitative agreement with the data. Although there were uncertainties in the models used due to approximations in the treatment of cascades from upper levels in heliumlike argon, ${ }^{55}$ the results provide further evidence that the excitation mechanisms of the heliumlike lines are not yet fully understood and that some atomic physics parameters may need to be revised.

\subsection{Neonlike Ions}

$X$-ray spectra from neonlike ions are more complex and cover a much wider spectral region than heliumlike spectra. Nevertheless, the spectra are simple enough that reasonable progress can be made in their interpretation. 
Interest in neonlike spectra origina'ed from astrophysical observations, and the early detailed atomic models were developed to interpret the $\mathrm{x}$ ray spectrum of neonlike iron in the sun. ${ }^{56,57}$ New studies have recently show $r_{2}$ the usefulness of neonlike $\mathrm{x}$-ray emission for diagnostic purposes in laser-produced plasmas and tokamaks. ${ }^{15,58,59}$ Interest in neonlike ions has also greatly intensified after the successful demonstration of $x$-ray amplification in neonlike selenium. ${ }^{60,61}$ These $\mathrm{x}$-ray lasing experiments have clearly shown the need for a thorough understanding of the excitation mechanisms of neonlike ions.

High-resolution $x$-ray spectra of highly charged neonlike ions have been observed in tokamaks from titanium $(Z=22)$ through europium $(Z=63) .{ }^{11,25,62-65}$ A spectrum of neonlike selenium obtained on the PLT tokamak with the USX spectrometer mentioned in Section 2 is shown in Fig. 7. A Grotrian diagram of the neonlike lines observed in selenium is given in Fig. 8. Electric dipole transitions are labelled $3 A-3 G$ according to the notation of Ref. 56. $M 2$ represents the magnetic quadrupole transition $\left(2 p_{3 / 2}^{5} 3 s_{1 / 2}\right)_{J=2}$ to the $2 p^{6}{ }^{1} S_{0}$ ground state; $E 2 L, E 2 M$, and $E 2 U$ denote $3 p \rightarrow 2 p$ electric quadrupole transitions. These transitions are of importance in $x$-ray lasing experiments because their upper levels correspond to the levels which have exhibited the strongest lasing gain. ${ }^{60,61}$ The lines labelled N47, F55, and F56 represent $3 d \rightarrow 2 p$ electric dipole transitions in sodiumlike and fluorinelike selenium, respectively. These lines have been used in Ref. 15 together with the neonlike electric dipole transition $3 d \rightarrow 2 p$, labelled $3 C$, to measure ion transport coefficients.

In order to study the temperature dependence of the line intensities of neonlike selenium, a new technique was employed in Ref. 65 which related Abel-inverted radial profiles of the spectral emission to the electron temperature profile. The temperature variation of the line ratio $3 \mathrm{~A} / 3 \mathrm{C}$ obtained with this technique is shown in Fig. 9. Here $3 A$ represents the strongest $3 p \rightarrow 2 s$ electric dipole transition in neonlike selenium. Both lines are excited predominantly by electron collisions. The data appear to be in reasonable agreement with predictions from model calcuiations. ${ }^{64,66}$ The calculations take into ac- 
count electron-impact excitation and radiative decay among the ground state and the 36 exciter levels which have an excited electron in the $n=3$ shell and a vacancy in the $n=2$ shell. The temperature variation of the ratios of other neonlike lines is in similar agreement with the model calculations as that of the ratio $3 A / 3 C .^{67}$

While the observed temperature variation is in reasonable agreement with theory, this is not true for the observed magnitude of some ratios. For example, the ratio of lines $M 2$ and $3 G$ in neonlike selenium (cf. Fig. 7 ) is measured to be twice as large as predicted by the model calculations. In contrast to lines $3 A$ and $3 C$, lines $M / 2$ and $3 G$ are strongly fed by cascades from higher levels (direct excitation contributes less than $10 \%$ to the total excitation of these lines in neonlike silver ${ }^{64}$ ), and they can be excited by innershell ionization of sodiumlike ions and recombination from fluorinelike ions. Hence, it is presumed that excitation processes involving neighboring charge states play a significant role. We have found similar discrepancies between data and predictions for the line ratio $M 2 / 3 G$ also in neonlike germanium ${ }^{68}$ and neonlike silver. ${ }^{64}$ The results are summarized in Table I. As is the case for the heliumlike spectra, a satisfactory modei which can account for the observed line intensities, given the plasma conditions in the experiment, has not yet been constructed.

\section{Measurements of Rate Coefficients}

Accurate (relative) rate coefficients can be inferred from the relative intensities of a given set of spectral lines provided the excitation mechanisms are well known. An example of this procedure is provided by a measurement of the dielectronic recombination rate for heliumlike iron in Ref, 47. Because the satellite spectrum of a heliumlike ion is well described by dielectronic recombination and innershell excitation, the dielectronic recombination rate can be inferred relative to the rate for direct excitation of line $w$ from the intensity of the satellite structure. ${ }^{47}$ However, as the discussion in Section 3 has shown, the excitation mechanisms of heliumlike or neonlike ions are 
generally not well known. Therefore, accurate rates cannot be inferred from the $x$-ray spectra of these ions, unless the experimental conditicns are chosen such that one particular excitation mechanism can be investigated at a time.

Recent developments in instrumentation have made it possible to identify and isolate individual excitation processes and thus have greatly enhanced the capabilities for measuring rate coefficients in tokamak plasmas. Highresolution $x$-ray spectrometers have typically viewed the center of the plasma along a fixed line of sight. However, recently spectrometers have been developed capable of viewing the plasma along different sightlines. For example, compact spectrometers which radially scan the plasma on a shot-to-shot basis have been installed on the Alcator $\mathrm{C}$ and PLT tokamaks. ${ }^{13,15}$ In a different approach, multiple sightlines are used for the vertical spectrometer on TFTR in order to view different region? of the plasma simultaneously. ${ }^{8.38}$ The profile information provided by these spectrometers has been used to isolate certain excitation mechanisms which have been obscured in sightline-integrated spectra. The development of a spectrometer with fast time resolution ${ }^{15}$ has made it possible to study transient phenomena in a single discharge and to identify individual population mechanisms which are blended in time-integrated spectra.

Using the radial scanning capabilities of a compact von Hámos spectrometer, ${ }^{13}$ Rice et al. have made measurements of the radial profiles of the transitions 1 snp $\rightarrow 1 s^{2}$ with $3 \leq n \leq \infty$ on the Alcator C tokamak. ${ }^{14,55}$ The data have shown charge-exchange between intrinsic neutral hydrogen to populate high- $n$ states of hydrogenic argon. In particular, charge exchange with neutral hydrogen populates the levels $n=9,10$, while charge exchange with excited hydrogen populates mainly levels $15 \leq n \leq 40 .{ }^{14} \mathrm{Be}$ cause this process is the dominant population mechanism for these high- $n$ levels, uncertainties due to other population mechanisms are small. Thus, it was possible to use the measurements to provide the first estimate of the charge-exchange cross section involving excited hydrogen, i.e. for the process $\mathrm{Ar}^{17+}\left(1 s^{2} S\right)+\mathrm{H}^{-}(n=2,3) \rightarrow \mathrm{Af}^{16+\cdot}\left(1 \sin { }^{2} P\right)+\mathrm{H}^{+}$.

Time- and space-resolved measurements of the spectrum of neontike se- 
lenium on PLT (Fig. 7) have enabled us to estimate the effective innershell ionization rate of sodiumlike selenium. ${ }^{65}$ Innershell ionization leaves the resulting neonlike ion in an excited state according to the process: $2 p^{6} 3 s+e \rightarrow$ $2 p^{5} 3 s+2 e$. This process, therefore, enhances the intensities of the neonlike transitions $3 s \rightarrow 2 p$, i.e., lines $3 F, 3 G$, and $M 2$ (cf. Fig. 8). Because these lines are also excited by a variety of other mechanisms, the contribution due to innershell ionization usually cannot be determined unequivocally. The problem was avoided by making measurements of the intensity profiles with $4 \mathrm{msec}$ time resolution immediately following the injection of selenium into the plasma ${ }^{65}$ This procedure enabled us to relate the intensity variations of lines $3 F, 3 G$, and $M 2$ directly to the relative abundance of sodiumlike selenium under identical plasma conditions. The results are illustrated in Fig. 10. The figure shows that the relative intensities of lines $3 F, 3 G$, and $M 2$ are larger when a higher concentration of sodiumlike selenium is in the plasma. From these data we have been able to infer a value of $8.3 \times 10^{-11}$ $\mathrm{cm}^{3} / \mathrm{sec}$ at $T_{e}=2 \mathrm{keV}$ for the innershell ionization rate. ${ }^{65}$ This value is 2.5 times larger than the value calculated by Sampson and Zhang in Ref. 69.

\section{Precise Wavelength Measurements}

A major concern of present-day atomic physics research is the development and testing of atomic structure theories which accurately describe relativist.c and quantum electrodynamical (QED) effects in highly charged ions. ${ }^{70,71}$ These effects are particularly important for high- $Z$ multi-electron ions where the treatment of electron correlations and the screening of radiative corrections introduces uncertainties into the calculations. ${ }^{72}$

Tokamak plasmas provide good conditions for absolute measurements of the transition energies of highly charged ions. The electron density is low so that line shapes are unaffected by density effects; and Doppler shifts which affect spectra from vacuum spark plasmas or beam-foil interactions are virtually absent. Despite these advantages tokamak $x$-ray spectroscopy has mainly been employed to make precise measurements of transitions within 
the same spectrum relative to each other. These measurements include measurements of the relative wavelengths of the $x$-ray transitions in heliumlike argon, ${ }^{64,73}$ potassium, ${ }^{64}$ scandium, ${ }^{65,73}$ titanium, ${ }^{6,8,44,65,74}$ vanadium, ${ }^{65,73}$ chromium, ${ }^{8,73,75}$ manganese, ${ }^{64,73}$ iron, ${ }^{8,42,64,76}$ and nickel. ${ }^{8,45,46}$ Similarly, $x$ ray spectroscopy has been used to measure the fine structure splitting of the hydrogenic lines $L y-\alpha_{1}$ and $L y-\alpha_{2}$ of argon, ${ }_{1}^{64,76}$ scandium, ${ }^{65}$ titanjum, ${ }^{65,77}$ chromium, ${ }^{65}$ iron, ${ }^{64}$ and nickel. ${ }^{45} \mathrm{X}$-ray measurements thus complement measurements of the fine structure from observations of $\Delta n=0, n=2$ transitions in the ultraviolet region, ${ }^{78-80}$ Wavelength measurements have been made relative to reference lines from $x$-ray tubes only of the $n=2 \rightarrow$ ! transitions in hydrogenic chlorine ${ }^{81}$ and argon ${ }^{82}$ on the Alcator $\mathrm{C}$ tokamak.

Recently we have utilized the capability of making precision relative wavelength measurements to measure wavelengths of heliumlike and neonlike $x$ ray transitions to within $0.1 \mathrm{~m} \AA$ or $30-50 \mathrm{ppm}$ with respect to sets of hydrogenic reference lines which were recorded concurrently. ${ }^{25,64}$ This technique is illustrated in Fig. 11. The figure shows the location of observed $\mathrm{x}$-ray transitions from heliumlike and neonlike ions in the wavelength region between 2.3 and $3.0 \AA$ together with the location of the hydrogenic reference lines. The large number of hydrogenlike reference lines minimizes errors which arise from uncertainties in the dispersion of the spectrometer. The Ly- $\alpha$ lines of hydrogenic ions are suitable calibration lines, because their wavelengths can be calculated with high precision from first principles. ${ }^{83,84}$ Because we use hydrogenic lines as references, our measurements do not test the accuracy of theoretical predictions of the single-electron, hydrogenic lines, but they check the atomic structure calculations for multi-electron ions, which are less certain than those for hydrogenic ions. ${ }^{2}$

A comparison of transition energies of the neonlike lines $M 2$ and $3 G$ measured on PLT for elements between $Z=47$ and 63 with multiconfigurational Dirac-Fock calculations which include QED corrections is shown in Fig. 12. The experimental energies are found consistently to be about $1.5 \mathrm{eV}$ higher than predicted. This discrepancy has been attributed to ground state electron correlations which were estimated to increase the theoretical transition 
energies by $1.7 \mathrm{eV} .^{25}$ For other transitions such as $3 F$ or $3 D$ (cf. Fig. S) the estimated value of the ground state correlation correction, however, did not account for observed discrepancies. ${ }^{25}$ Detailed, relativistic calculations of the electron correlations are needed to address this discrepancy.

The self-energy contribution to the energy of transitions in multi-electron jons has not yet been calculated from first principles. ${ }^{72}$ Thus its value remains uncertain, and measurements of the self-energy in multi-electron ions are needed to determine the size of the effect. In neonlike ions transitions of the type $3 p \rightarrow 2 s$ (lines $3 A$ and $3 B$, cf. Figs. 7 and 8 ) are the most affected by contributions from radiative effects. ${ }^{23}$ Assuming that the Dirac energy, Breit interaction, vacuum polarization, and residual electron correlation energies can be calculated accurately, we can determine the self-energy contribution for these transitions from the experimental transition energies. ${ }^{65}$ The results are listed in Table II. Here we have also listed self-energies calculated using an effective-charge approach. ${ }^{85}$ This approach is an ad hoc method to account for screening of the nuclear potential. Also listed are the self-energies calculated from unscreened, bare hydrogenic wavefunctions.

Table II shows that the experimental values are closest to the hydrogenic self-energies. The error in the experimental value for the self-energy is dominated by the uncertainties in the calculated values of the residual electron correlation energies and may be as large as $0.7 \mathrm{eV} .{ }^{65}$ However, even if the value of the residual correlation energy were reduced by $0.7 \mathrm{eV}$, the experimental values for the self-energy would on average exceed the screened values significantly. The result implies that present methods for estimating the selfenergy in multi-electron jons are inadequate and that calculations from first principles are needed.

Systematic differences have also been observed between calculated transition energies for lines $w$ of heliumlike ions and values measured on PLT. The measurements are described in Ref. 86. The transition energy of lines $w$ in heliumlike potassium, scandium, titanium, vanadium, chromium, and iron were found to be consistently larger than predicted by several different types of calculations. The differences are plotted in Fig. 13 and are consistent with 
differences noted by Deslattes ${ }^{87}$ in an examination of data from accelerator facilities. The nature of the differences is not yet understood. The wavelengths of a large number of heliumlike resonance lines have recently also been measured in a vacuum spark source. ${ }^{88}$

\section{Conclusion}

We have presented an overview of various physics aspects of highly charged jons which have been addressed recently on tokamaks: testing of atomic physics models, measurements of rate coefficients, and precise wavelength determinations. Our discussion has focussed on recent developments brought about by the achievement of high-electron-temperature plasmas, progress in instrumentation, and new measurement schemes.

Remarkable agreement between measurements and theoretical predictions can be noted in many areas of investigation. However, in this review we have placed special emphasis on atomic physics issues which are unresolved in the hope that this will stimulate new research. These issues concern the population mechanisms of excited levels in heliumlike and neonlike ions, the magnitude of the recombination rates, and multi-electron effects on the transition energies of highly charged ions.

There are a variety of issues which we have not addressed in this review. For instance, charge transfer between energetic neutral hydrogen and highly charged ions is a major process in neutral-beam-heated plasmas, and the polarization of $x$ rays needs to be understood in tokamak discharges which have a non-Maxwellian component in the electron distribution function.

As the goal of ignition and burning is approached in controlled thermonuclear fusion research, diagnostics will be needed which provide information on the density, temperature, transport, slowing down, and confinement time of the 3.5-MeV alpha particles produced in the fusion reactions. Interactions of fast alphas with highly charged ions may provide the key for the development of such diagnostics. Such processes, however, still need to be identified. 


\section{Acknowledgments}

We gratefully acknowledge the help and support of many colleagues, especially R.S. Walling, M. H. Chen, J. H. Scofield, R. A. Hulse, and E. Hinnov. The electron temperature and density profiles in Fig. 1 were measured by R. E. Bell. Encouragement for writing this article was provided by R. J. Fortser. We thank the members of the PLT and TFTR operating crews as well as J. Gorman and J. Lehner for their technical support. •

This work was performed under the auspices of the U.S. Department of Energy by the Lawrence Livermore National Laboratory under contract No. W-7405-ENG-48, and by the Princeton Plasma Physics Laboratory under contract No. DE-AC02-76-CHO-3073. 


\section{References}

${ }^{1}$ C. De Michelis and M. Mattioli, Nucl. Fusion 21, 677 (1981).

${ }^{2}$ R. Bartiromo, in Proceedings of the Course on Diagnostics for Fusion Reastor Conditions, Varenna, Italy, 1982 edited by P. E. Stott et al. (Commission of the European Communities, Brussels, 1983), Vol. I, p. 123.

${ }^{3}$ K. W. Hill, P. Beiersdorfer, M. Bitter, E. Fredrickson, S. von Goeler, H. Hsuan, K. McGuire, N. R. Sauthoff, S. Sesnic, and J. E. Stevens, in Course and Workshop on Basic and Advanced Dingnostic Techniques for Fusion Plasmas, Varenna, Italy, 1986 edited by P. Stott et al. (Office for Official Publications of the European Communities, Luxembourg, 19S7): Vol. I, p. 169.

${ }^{4}$ K. W. Hill, P. Beiersdorfer, M. Bitter, E. Fredrickson, S. von Goeler, H. Hsuan, L. C. Johnson, S.-L. Liew, K. McGuire, V. Paré, N. R. Sauthoff, S. Sesnic, and J. E. Stevens, in Course and Workshop on Basic and Advanced Diagnosic Techniques for Fusion Plasmas, Varenna, Italy, 1980 edited by P. Stott et al. (Office for Official Publications of the European Communities, Luxembourg, 1987), Vol. I, p. 201.

${ }^{5}$ M. Bitter, S. von Goeler, R. Horton, M. Goldman, K. Hill, N. R. Sauthoff, and W. Stodiek, Phys. Rev, Lett. 42, 304 (1979).

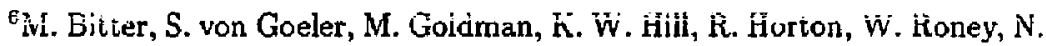
Sauthoff, and W. Stodiek, in Temperature, its Measurement and Control in Science and Industry, edited by S. F. Schooley (American Institute of Physics, New York, 1982), Vol. 5, p. 693.

${ }^{7}$ M. Bitter et al., Plasma Phys. Controlled Fusion 29, 1235 (1985).

${ }^{8}$ M. Bitter, H. Hsuan, J. E. Rice, K. W. Hill, M. Diesso, B. Grek, R. Hulse, D. W. Johnson, L. C. Johnson, and S. von Goeler, Rev. Sci. Instrum. 59, 2131 (1988). 
${ }^{9}$ H. Hsuan, M. Bitter, J. E. Rice, K. W. Hill, L. Johnson, S. L. Liew, S. D. Scott, and S. von Goeler, Rev. Sci. Instrum. 59, 2127 (1983).

${ }^{10} \mathrm{~K}$, W. Hill, S. von Goeler, M. Bitter, L. Campbell, R. D. Cowan, B. Fraenkel, A. Greenberger, R. Horton, J. Hovey, W. Roney, N. R. Sauthoff, and W. Stodiek, Phys. Rev. A 19, 1770 (1979).

${ }^{11}$ S. von Goeler, M. Bitter, S. Cohen, D. Eames, K. W. Hill, D. Hills, R. Hulse, G. Lenner, D. Manos, P. Roney, N. Sauthoff, S. Sesnic, W. Stodiek, F. Tenney, and J. Timberlake, in Proceedings of the Course on Diagnostics for Fusion Reactor Conditions, Varenna, Italy, 1982 edited by P. E. Stott et al. (Commission of the European Communities, Brussels, 1983), Vol. I, p. 109.

${ }^{12}$ TFR Group, Nucl. Fusion 23, 559 (1983).

${ }^{13}$ E. Källne, J. Källne, E. S. Marmar, and J. E. Rice, Phys. Scripta 31, 551 (1985).

${ }^{14}$ J. E. Rice, E. S. Marmar, J. L. Terry, E. Källne, and J. Källne, Phys. Rev. Lett. 56, $50(1986)$.

${ }^{15}$ P. Beiersdorfer, S. von Goeler, M. Bitter, K. W. Hill, R. A. Hulse, R. S. Walling, Rev. Sci. Instrum. 60, 895 (1989).

${ }^{16}$ A. H. Gabriel, Mon. Not. R. Astron. Soc. 160, 99 (1972).

17J. Dubau and S. Volonté, Rep. Prog. Phys. 43, 199 (1980).

${ }^{18}$ E. S. Marmar, J. L. Cecchi, and S. A. Cohen, Rev. Sci. Instrum. 46, 1149 (1975).

${ }^{19} \mathrm{~J}$. Timberlake, S. Cohen, C. Daughney, and D. Manos, J. Vac. Sci. Technol. A 1, 841 (1983).

${ }^{20}$ D. V. Orlinskij and G. Magyar, Nucl. Fusion 28, 611 (1988). 
${ }^{21} \mathrm{~J}$. Hosea, J. R. Wilson, W. Hooke, M. Ono, E. Mazzucato, R. Bell, S. Bernabej, A. Cavallo, T. K. Chu, S. Cohen, P. L. Colestock, G. Gammel, G. J. Greene, G. Hammett, H. Hsuan, R. Kaita, D. McNeill, R. Motley, K. Sato, J. Stevens, S. Suckewer, S. von Goeler, and A. Wouters, Plasma Phys. Controlled Fusion 28, 1241 (1986).

${ }^{22}$ J. E. Stevens, R. Bell, S. Bernabei, A. Cavallo, T. K. Chu, P. Colestock, W. Hooke, J. Hosea, F. Jobes, T. Luce, E. Mazzucato, R. Motley, R. Pinsker, S. von Goeler, and J. R. Wilson, Nucl. Fusion 28, 217 (1988).

${ }^{23}$ R. E. Bell, S. Bernabej, A. Cavallo, T. K. Chu, T. Luce, R. Motley, M. Ono, J. Stevens, and S. von Goeler, Phys. Rev. Lett. 60, 1294 (1988).

${ }^{24}$ J. D. Strachan et al., Phys. Rev. Lett. 1004, 58 (1987).

${ }^{25}$ P. Beiersdorfer, S. von Goeler, M. Bitter, E. Hinnov, R. Bell, S. Bernabei, J. Felt, K. W. Hill, R. Hulse, J. Stevens, S. Suckewer, J. Timberlake, A. Wouters, M. H. Chen, J. H. Scofield, D. D. Dietrich, M. Gerassimento, E. Silver, R. S. Walling, and P. L. Hagelstein, Phys. Rev. A 37, 4153 (1988).

${ }^{26}$ V. Alikaev et al., Plasma Phys. Controlled Fusion 29, 1285 (1987).

${ }^{27}$ R. A. Hulse, Nucl. Technol. Fusion 3, 259 (1983).

${ }^{28}$ S. A. Cohen, J. L. Cecchi, and E. S. Marmar, Phys. Rev. Lett. 35, 1507 (1975).

${ }^{29}$ E. S. Marmar, J. E. Rice, and S. L. Allen, Phys. Rev. Lett. 45, 2025 (1980).

${ }^{30}$ E. S. Marmar, J. E. Rire, J. L. Terry, and F. H. Seguin, Nucl. Fusion 22, 1567 (1982).

${ }^{31}$ R. J. Fonck, M. Finkenthal, R. J. Goldston, D. L. Herndon, R. A. Hulse, R. Kaita, and D. D. Meyerhofer, Plyys. Rev. Lett. 49, 737 (1982). 
${ }^{32}$ R. C. Isler, L. E. Murray, E. C. Crume, C. E. Bush, J. L. Dunlap, P. H. Edmonds, S. Kasai, E. A. Lazarus, M. Murakami, G. H. Neilson, V. K. Paré, S. D. Scott, C. E. Thomas, and A. J. Wootton, Nucl. Fusion 23, 1017 (1983).

${ }^{33}$ R. J. Fonck and R. A. Hulse, Phys. Rev. Lett. 52, 530 (1984).

${ }^{34}$ H. H. Johann, Z. Phys. 69, 185 (1931).

${ }^{35}$ P. Platz, J. Ramette, E. Belin, C. Bonnelle, and A. Gabriel, J. Phys. E 14, 448 (1981).

${ }^{36}$ R. Bartiromo, R. Giannella, M. L. Apicella, F. Bombarda, S. Mantovani, and G. Pizzicarolli, Nucl. Instrum. Methods 225, 378 (1984).

${ }^{37}$ I. W. Hill, M. Bitter, M. Tavernier, M. Diesso, S. von Goeler, G. Johnson, L. C. Johnson, N. R. Sauthoff, N. Schechtman, S. Sesnic, F. Tenney, and K. M. Young, Rev. Sci. Instrum. 56, 1165 (1985).

${ }^{38}$ M. Bitter, K. W. Hill, S. Cohen, S. von Goeler, H. Hsuan, L. C. Johnson, R. Raftopulos, M. Reale, N. Schechtman, S. Sesnic, F. Spinos, J. Timberlake, S. Weicher, N. Young, and K. M. Young, Rev. Sci. Instrum. 57, 2145 (1986).

${ }^{39}$ R. Bartiromo, F. Bombarda, R. Giannella, S. Mantovani, L. Panaccione, and G. Pizzicaroli, Rev. Sci. Instrum. 60, 237 (1989).

${ }^{40}$ L. v. Hámos, Ann. der Physik 17, 716 (1933).

'E. Källne and J. Källne, Phys. Scripta T17, 152 (1987).

${ }^{42}$ M. Bitter, K. W. Hill, N. R. Sauthoff, P. C. Efthimion, E. Merservey, W. Roney, S. von Goeler, R. Horton, M. Goldman, and W. Stodiek, Phys. Rev. Lett. 43, 129 (1979).

${ }^{43}$ M. Bitter, S. von Goeler, K. W. Hill, R. Horton, D. Johnson, W. Roney, N. Sauthoff, E. Silver, and W. Stodiek, Phys. Rev. Lett. 47, 921 (1981). 
${ }^{44}$ M. Bitter, K. W. Hill, M. Zarnstorf, S. von Goeler, R. Hulse, L. C. Johnson, N. R. Sauthoff, S. Sesnic, and K. M. Young, Phys. Rev. A 32, 3011 (1985).

${ }^{45}$ F. Bombarda, R. Giannella, E. Källne, G. J. Tallents, F. Bely-Dubau, P. Faucher, M. Cornille, J. Dubau, and A. H. Gabriel, Phys. Rev. A 37, 504 (1988).

${ }^{46}$ H. Hsuan, M. Bitter, K. W. Hill, , von Goeler, B. Grek, D. Johnson, C. P. Bhalla, K. R. Karim, F. Bely-Dubau, and P. Faucher, Phys. Rev. A 35,4280 (1987).

${ }^{47}$ F. Bely-Dubau, M. Bitter, J. Dubau, P. Faucher, A. H. Gabriel, K. W. Hill, S. von Goeler, N. Sauthoff, and S. Volonté, Phys. Lett. 93A, 189 (1983).

${ }^{48}$ T. Kato, S. Morita, K. Masai, and S. Hayakawa, Phys. Rev. A 36, 795 (1987).

${ }^{49}$ T. Kato and K. Masai, J. Phys. (Paris) 49, C1 (1988).

${ }^{50}$ M. L. Apicella, R. Bartiromo, F. Bombarda, and R. Giannella, Phys. Lett. 98A, 174 (1983).

${ }^{51}$ R. Bartiromo, F. Bombarda, and R. Giannella, Phys. Rev. A 32, 531 (1985).

${ }^{52}$ P. Lee, A. J. Lieber, R. P. Chase, and A. K. Pradhan, Phys. Rev. Lett. 55, 386 (1985).

${ }^{53}$ P. Lee, A. J. Lieber, A. K. Pradhan, and Y. Xu, Phys. Rev. A 34, 3210 (1986).

${ }^{54}$ E. Källne, J. Kätlne, A. Dalgarno, E. S. Marmar, J. E. Rice, and A. K. Pradhan, Phys. Rev. Lett. 52, 2245 (1984).

${ }^{35}$ J. E. Rice, E. S. Marmar, E. Källne, and J. Källne, Phys. Rev. A 35, 3033 (1987).

${ }^{56}$ M. Loulergue and H. Nussbaumer, Astron. Astrophys. 24, 209 (1973). 
${ }^{57}$ M. Loulergue and H. Nussbaumer, Astron. Astrophys. 45, 125 (1975).

${ }^{58}$ W. H. Goldstein, R. S. Walling, J. Bailey, M. H. Chen, R. Fortner, M. Klapisch, T. Phillips, and R. E. Stewart, Phys. Rev. Leit. 58, 2300 (1987).

${ }^{59}$ B. K. F. Young, A. L. Osterheld, R. S. Walling, W. H. Goldstein, T. W. Phillips, R. E. Stewart, G. Charatis, and Gar. E. Busch, Phys. Rev. Lett. 62,1266 (1989).

${ }^{60}$ D. L. Matthews, P. L. Hagelstein, M. D. Rosen, M. J. Eckart, N. M. Ceglio, A. U. Hazi, H. Medecki, B. J. MacGowan, J. E. Trebes, B. L. Whitten, E. M. Campbell, C. W. Hatcher, A. M. Hawryluk, R. L. Kauffman, L. D. Pleasance, G. Rambach, J. H. Scofield, G. Stone, and T. A. Weaver, Phys. Rev. Lett. 54, 110 (1985).

${ }^{61}$ T. N. Lee, E. A. McLean, and R. C. Elton, Phys. Rev. Lett. 59, 1185 (1987).

${ }^{\circ 2}$ M. Klapisch, A. Bar Shalom, J. L. Schwob, B. S. Fraenkel, C. Breton, C. de Michelis, M. Finkenthal, and M. Mattioli, Phys. Lett. 69A, 34 (1978).

${ }^{63}$ E. Källne, J. Källne, and R. D. Cowan, Phys. Rev. A 27, 2682 (1983).

${ }^{64}$ P. Bejersdorfer, M. Bitter, S. von Goeler, S. Cohen, K. W. Hill, J. Timberlake, R. S. Walling, M. H. Chen, P. L. Hagelstein, and J. H. Scofield, Phys. Rev. A 34, 1297 (1986).

${ }^{65} \mathrm{P}$. Beiersdorfer, Ph.D. Thesis, Princeton University (1988).

${ }^{66}$ R. S. Walling, M. H. Chen, A. U. Hazi, K. J. Reed, J. H. Scofield and C. B. Tartar, Bull. Am. Phys. Soc. 30, 1118 (1985).

${ }^{67}$ P. Beiersdorfer, R. S. Walling, M. Bitter, S. von Goeler, and E. Hinnov, Bull. Am. Phys. Soc. 33, 945 (1988). 
${ }^{68}$ P. Beiersdorfer, M. Bitter, S. Cohen, D. Edmondson, K. Hill, E. Hinnov, J. Timberlake, S. Sesnic, and S. von Goeler, Bull. Am. Phys. Soc. 30, 1116 (1985).

${ }^{69}$ D. H. Sampson and H. Zhang, Phys. Rev. A 36, 3590 (1987).

${ }^{70}$ Atomic Theory Workshop on Relativistic and QED Effects in Heavy Atoms, AIP Conference Proceedings No. 136, edited by H. P. Kelly and Y.-K. Kïm (AIP, New York, 1985).

${ }^{71}$ L. N. Ivanov, E. P. Ivanova, and E. V. Aglitsky, Phys. Rep. 164, 316 (1988).

72P. J. Mohr, Nucl. Instrum. Methods B9, 459 (1985).

${ }^{73}$ TFR Group, M. Cornille, J. Dubau, and M. Loulergue, Phys. Rev. A 32, 3000 (1985).

${ }^{74}$ P. Lee, A. J. Lieber, and S. S. Wojtowicz, Phys. Rev. A 31, 3996 (1985).

${ }^{75}$ TFR Group, J. Dubau, and M. Loulergue, J. Phys. B 15, 1007 (1982).

${ }^{76}$ R. Bartiromo, F. Bombarda, and R. Giannella, Nucl. Instrum. Methods B9, 679 (1985).

${ }^{7 M}$ M. Bitter, S. von Goeler, S. Cohen, K. W. Hill, S. Sesnic, F. Tenney, J. Timberlake, U. I. Safronova, L. A. Vainshtein, J. Dubau, M. Loulergue, F. Bely-Dubau, and I. Steenman-Clark, Phys. Rev. A 29, 661 (1984).

${ }^{78}$ M. F. Stamp, I. A. Armour, N. J. Peacock, and J. D. Silver, J. Phys. B 14, 3551 (1981).

${ }^{79}$ E. Hinnov, Nucl. Instrum. Methods 202, 381 (1982).

${ }^{80}$ N. J. Peacock, M. F. Stamp, and J. D. Silver, Phys. Scripta T8, 10 (1984).

${ }^{81}$ E. Källne, J. Källne, P. Richard, and M. Stöckli, J. Phys. B 17, L115 (1984). 
${ }^{82}$ E. S. Marmar, J. E. Rice, E. Källne, J. Källne, and R. E. LaVilla, Phys. Rev. A 33, 774 (1986).

${ }^{83}$ P. Mohr, At. Data Nucl. Data Tables 29, 453 (1983).

${ }^{8}$ W. R. Johnson and G. Soff, At. Data Nucl. Data Tables 33, 405 (1985).

${ }^{85}$ B. J. McKenzie, I. P. Grant, and P. H. Norrington, Comput. Phys. Commun. 21, 233 (1980).

${ }^{86}$ P. Beiersdorfer, M. Bitter, S. von Goeler, and K. W. Hill, Phys. Rev. A (in press); Lawrence Livermore National Laboratory Report No. UCRL. I00132.

${ }^{87}$ R. D. Deslattes, Nucl. Instrum. Methods B24/25, 52 (1987).

${ }^{88}$ E. V. Aglitsky, P. S. Antsiferov, S. L. Mandelstam, A. M. Panin, U. I. Safronova, S. A. Ulitin, and L. A. Vainshtein, Phys. Scripta 38, 136 (1988).

${ }^{89} \mathrm{P}$. Indelicato, private communication (1988).

${ }^{90}$ G. W. F. Drake, Can. J. Phys. 66, 586 (1988).

${ }^{91}$ L. A. Vainshtein and U. I. Safronova, Phys. Scripta 31, 519 (1985). 
TABLE I. Comparison of theoretical and experimental intensity ratios of lines $M 2$ and $3 G$ for $\mathrm{Ge}^{22+}$ (Ref. 68), $\mathrm{Se}^{24+}$ (Ref. 67), and $\mathrm{Ag}^{37+}$ (Ref. 64). The theoretical values are from Ref. 66, and are calculated using a 37level collisional-radiative model. The electron temperature assumed in the calculations is given in the last column and corresponds to the temperature of the measurements.

\begin{tabular}{cccc}
\hline \hline Element & $\begin{array}{c}M 2 / 3 G \\
\text { Experiment }\end{array}$ & $\begin{array}{c}M 2 / 3 G \\
\text { Theory }\end{array}$ & $\begin{array}{c}T_{e} \\
(k e V)\end{array}$ \\
\hline$G e$ & 0.83 & 0.45 & 1.5 \\
$S e$ & 0.80 & 0.41 & 2.0 \\
$\mathrm{Ag}$ & 0.74 & 0.38 & 3.0 \\
\hline \hline
\end{tabular}


TABLE Il. Comparison of theoretical and experimental values for the selfenergies of the $3 p \rightarrow 2 s$ transitions $3 A$ and $3 B$ in $\mathrm{Ag}^{37+}, \mathrm{Xe}^{44+}$, and $\mathrm{La}^{47+}$. $\mathrm{E}_{\text {measured }}$ is the transition energy reported in Ref. 64 for silver and in Ref. 25 for xenon and lanthanum. The theoretical energies have been obtained form multiconfigurational Dirac-Fock calculations and are the same as in Ref. 25. $E_{\text {Coulomb }}$ is the relativistic Coulomb energy, $E_{B_{r e i t}}$ is the transverse Breit correction, $E_{V P}$ is the vacuum polarization energy, and $E_{c}$ is the residual correlation energy. The experimental self-energy $\mathrm{SE}_{\exp }$ is obtained by subtracting the theoretical energies from the measured transition energy. $\mathrm{SE}_{\text {screen }}$ is the self-energy computed using the effective-charge approach, and $\mathrm{SE}_{\text {bare }}$ is the self-energy computed assuming bare, unscreened hydrogenic wavefunctions.

\begin{tabular}{cccccccccc}
\hline \hline Transition & Element & $\begin{array}{c}\mathrm{E}_{\text {moasured }} \\
(\mathrm{eV})\end{array}$ & $\begin{array}{c}\mathrm{E}_{\text {Coulomb }} \\
(\mathrm{eV})\end{array}$ & $\begin{array}{c}\mathrm{E}_{\text {Breit }} \\
(\mathrm{eV})\end{array}$ & $\begin{array}{c}\mathrm{E}_{V P} \\
(\mathrm{eV})\end{array}$ & $\begin{array}{c}\mathrm{E}_{C} \\
(\mathrm{eV})\end{array}$ & $\begin{array}{c}\mathrm{SE}_{\text {exp }} \\
(\mathrm{eV})\end{array}$ & $\begin{array}{c}\mathrm{SE}_{\text {acreen }} \\
(\mathrm{eV})\end{array}$ & $\begin{array}{c}\mathrm{SE}_{\text {bare }} \\
(\mathrm{eV})\end{array}$ \\
\hline $3 \mathrm{3A}$ & Silver & 3646.54 & 3654.93 & -3.73 & +0.45 & -0.90 & -4.2 & -3.5 & -4.6 \\
& Xenon & 5039.93 & 5053.18 & -6.09 & +0.86 & -0.91 & -7.1 & -5.9 & -7.6 \\
& Lanthanum & 5721.21 & 5737.04 & -7.37 & +1.11 & -0.92 & -8.7 & -7.3 & -9.5 \\
$3 B$ & Silver & 3598.47 & 3605.64 & -2.98 & +0.44 & -0.90 & -3.7 & -3.5 & -4.6 \\
& Xenon & 4949.20 & 4961.57 & -4.84 & +0.84 & -0.91 & -7.5 & -6.0 & -7.7 \\
\hline
\end{tabular}




\section{Figures}

FIG. 1. Electron temperature profiles measured with Thomson scattering on the PLT tokamak. The discharge parameters are (a) open circles; ohmic heating only, hydrogen plasma, $I_{P}=450 \mathrm{kA}, B_{T}=31.3 \mathrm{kG}$; (b) solid circles: Lower-hybrid heating with $P_{L H}=650 \mathrm{~kW}$, hydrogen plasma with some neon component, $I_{P}=530 \mathrm{kA}, B_{T}=31.4 \mathrm{kG}$. The line-averaged density for each case is $1 \times 10^{13} \mathrm{~cm}^{-3}$. The electron density profile is shown in the inset.

FIG. 2. Minimum central electron temperature necessary to detect x-ray line emission from neonlike ions of atomic number $Z$ with the PLT highresolution Bragg-crystal spectrometer. The line-averaged electron density in each case is $1 \times 10^{13} \mathrm{~cm}^{-3}$. The solid line is drawn as a visual aid only.

FIG. 3. Radial distribution of selenium ions in PLT for the measured electron temperature profile shown. (a) profiles calculated assuming coronal equilibrium; (b) profiles calculated assuming a diffusion coefficient, $D=5 \times 10^{3}$ $\mathrm{cm}^{2} / \mathrm{sec}$.

FIG. 4. Satellite spectrum of Ti XXI, Ti XX, and Ti XIX. The notation used is that of Gabriel. ${ }^{16}$ The data have been recorded with a high-resolution Br. gg-crystal spectrometer on TFTR. The plasma parameters are $T_{e}(0)$ $=1.8 \mathrm{keV}, n_{e}(0)=2.7 \times 10^{13} \mathrm{~cm}^{-3}, I_{P}=1 \mathrm{MA}$. The solid curve in (a) represents a theoretically predicted spectrum. The contributions from various processes are shown in (b)-(d). The theoretical intensitites lor lines $x, y$, and $z$ in (b) only include direct excitation from the ground state.

FIG. 5. Comparison of the measured relative intensities of the triplet lines $x$, $y$, and $z$ in heliumlike titanium (points) with calculations which include direct excitation, cascade feeding, and contributions from resonances. The data were obtained from TFTR plasmas at the major and minor radij indicated. 
FIG. 6. Satellite spectra of Fe XXV, Fe XXIV, and Fe XXIII observed on TFTR with $n_{e}(0)=1.5 \times 10^{13} \mathrm{~cm}^{-3}$ and $I_{P}=0.7$ MA. The notation is that of Gabriel. ${ }^{16}$ Unlike the spectrum in (a) the spectrum in (b) is recorded during a time interval when significant amcunts of Fe XXVI are in the plasma.

FIG. 7. Spectrum of neonlike selenium covering the wavelength region $7.20-$ $9.00 \AA$. The spectrum was recorded on PLT with a vacuum crystal spectrometer in the Johann geometry. All neonlike transitions as well as the sodiumlike transition $N 47$ and the fluorinelike transitions $F 55$ and F54 have been labelled. The unmarked features are due to transitions in sodiumlike, fluorinelike, and oxygenlike selenium. The spectrum is a composite of four individual spectra joined at the wavelengths indicated by the solid triangles.

FIG. 8. Grotrian diagram of selected energy levels in Se XXV. Levels have been designated using jj coupling, i.e., $\left(j_{1}, j_{2}\right)_{J}$, where $j_{1}, j_{2}$, and $J$ are the angular momentum of the core state and of the excited electron, and the total angular momentum, respectively. Transitions to the ground state are labelled using the same notation as in Fig. 7.

FIG. 9. Relative intensity of line $3 A$ in neonlike selenium versus electron temperature. The theoretical intensity has been calculated by a 37-jevel collisional-radiative model. ${ }^{66}$ The intensity of line $3 A$ is normalized to the intensity of line $3 C$.

FIG. 10. Variation of the relative intensities of the $3 s \rightarrow 2 p$ transitions $3 F$. $3 G$, and $M 2$ in Se XXV with the relative abundance of Se XXIV'.

FIG. 11. Overview of $\mathrm{x}$-ray transitions observed in the wavelength region 2.30-3.00 $\AA$ showing the location of spectra from hydrogenlike, heliumlike, and neonlike ions. The bydrogenlike lines are used as wavelengtl. references. 
FIG. 12. Comparison of measured and calculated energies for transitions $\left(2 p_{3 / 2}^{5} 3 s\right)_{J=1,2} \rightarrow 2 p^{6}$ in various neonlike ions. The transitions are labelled $3 G$ and $M 2$, respectively.

FIG. 13. Differences in transition energies between data obtained on PL'T and calculations for the transition $1 s 2 p{ }^{1} P_{1} \rightarrow 1 s^{2}{ }^{1} S_{0}$ in various heliumlike ions. The calculations are by: (a) Indelicato, Ref. 89; (b) Drakc, Ref. 90; and (c) Vainshtein and Safronova, Ref. 91. 


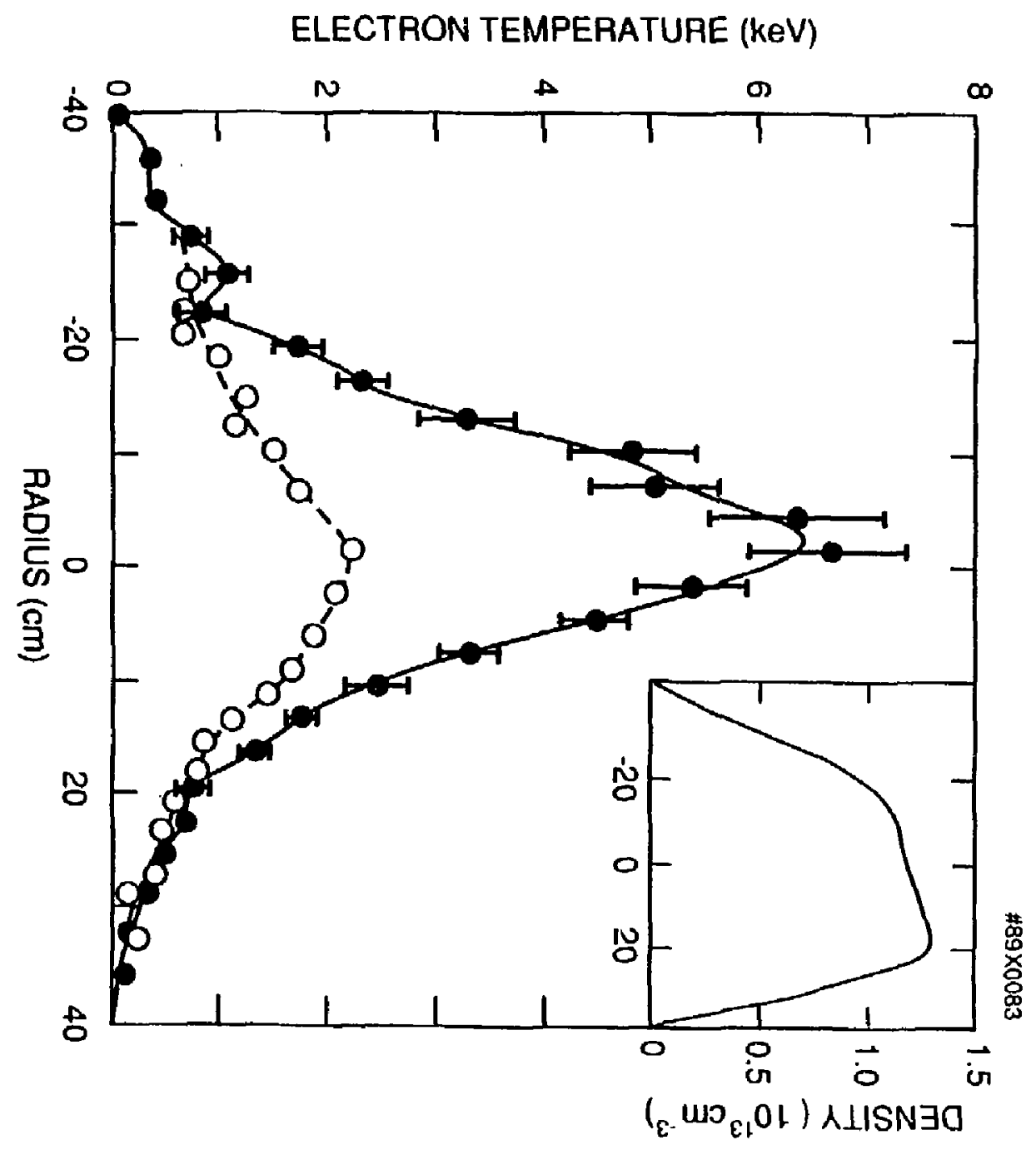




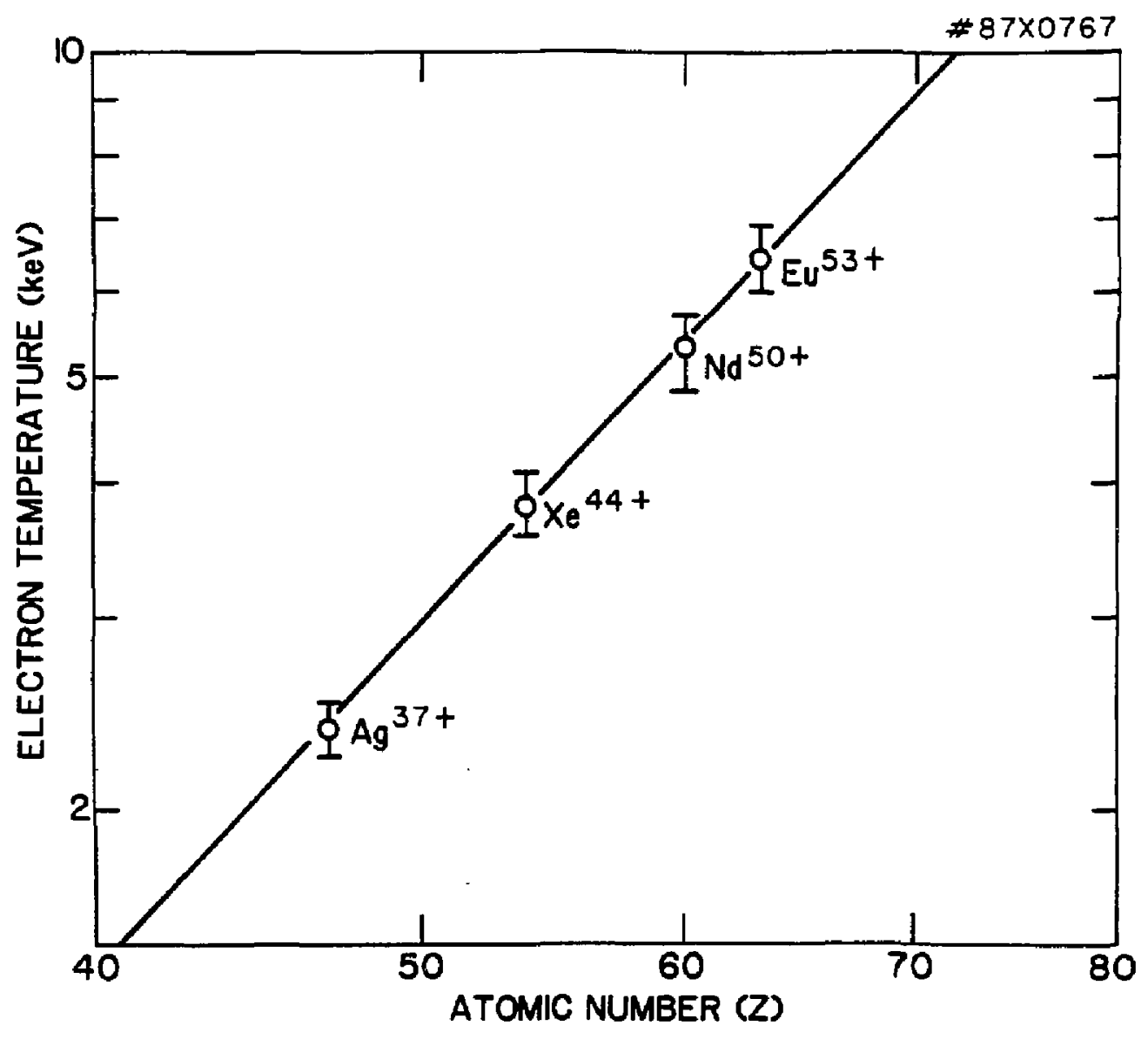

Fig. 2 

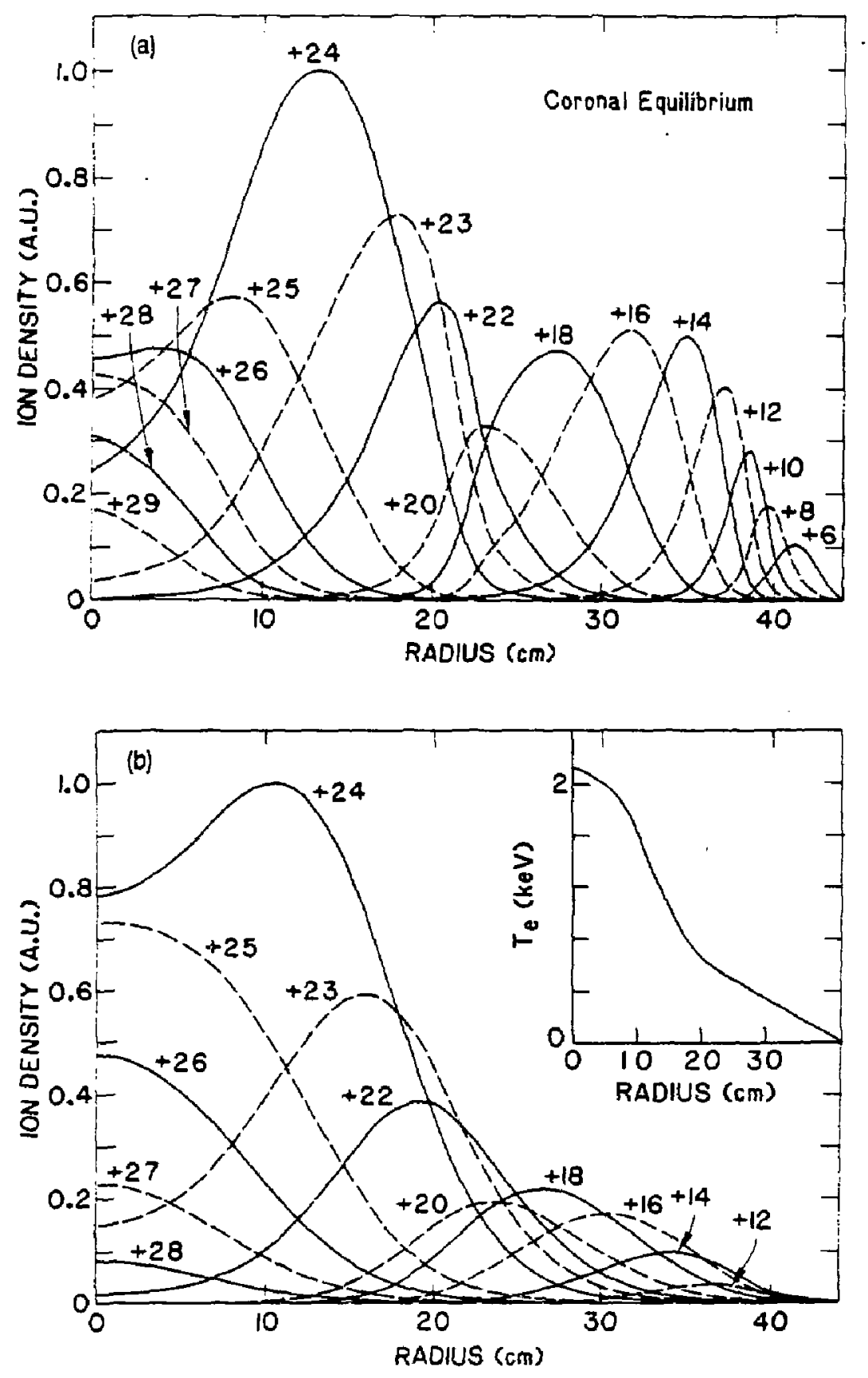

Eig. 3 


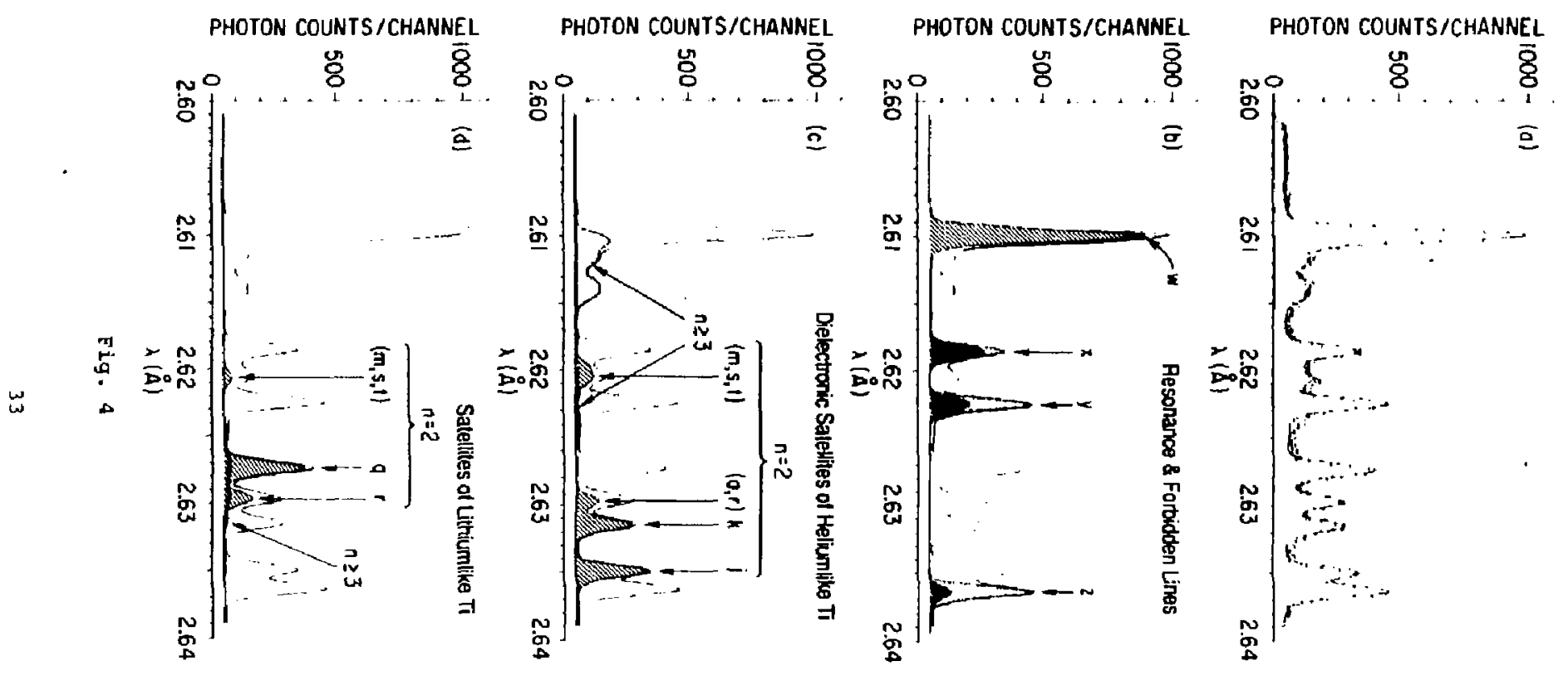



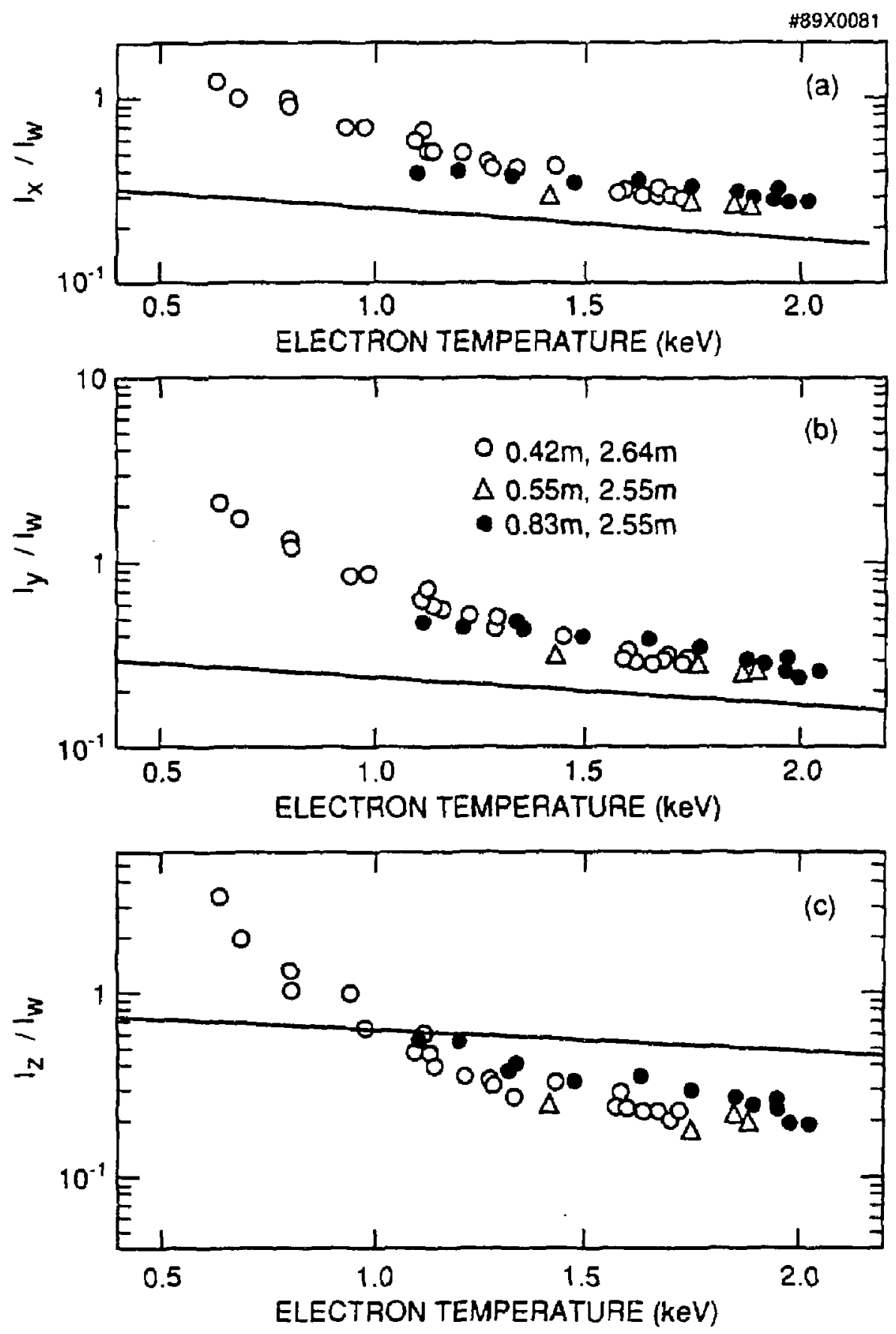

Fig. 5 


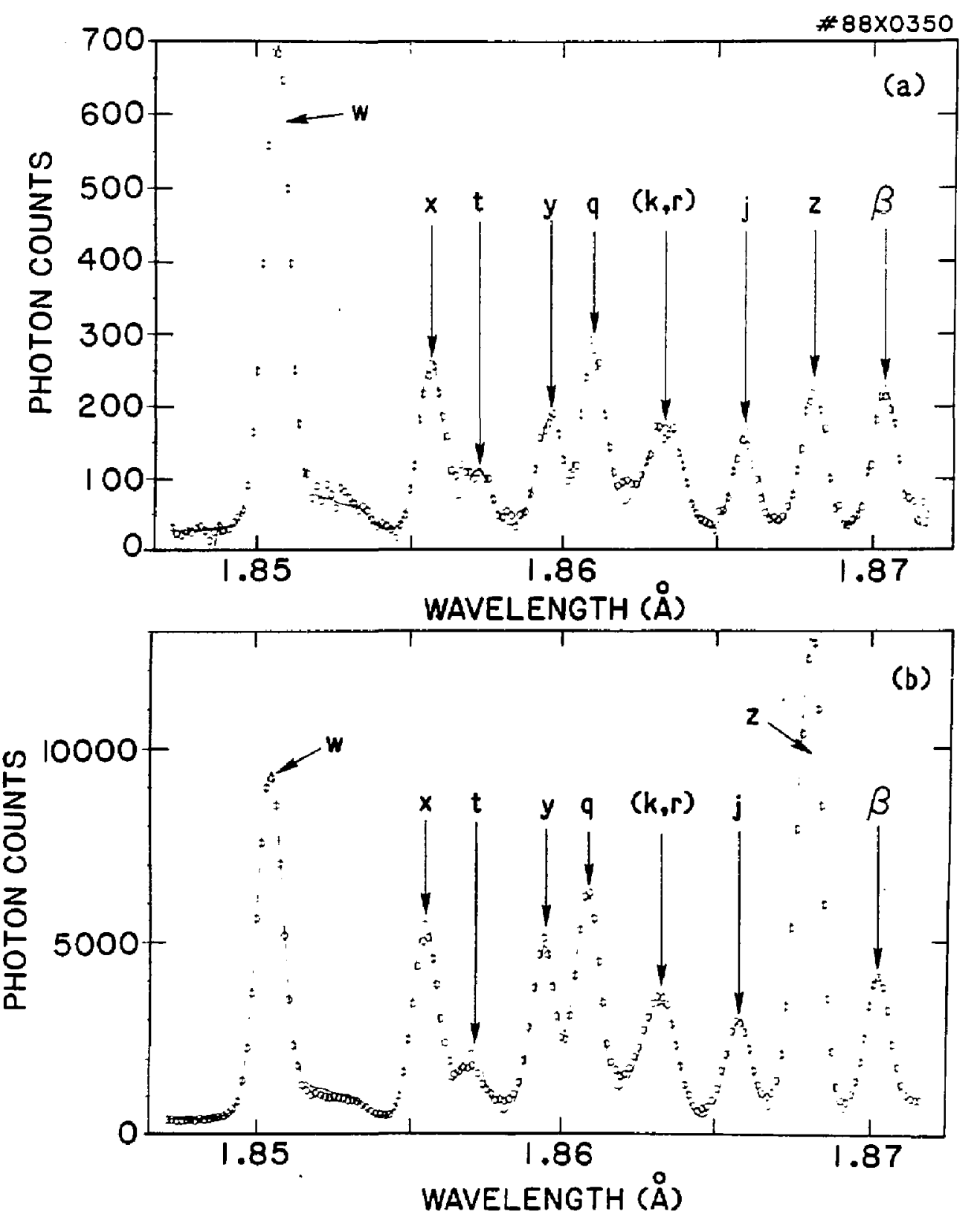

Fig. 6 


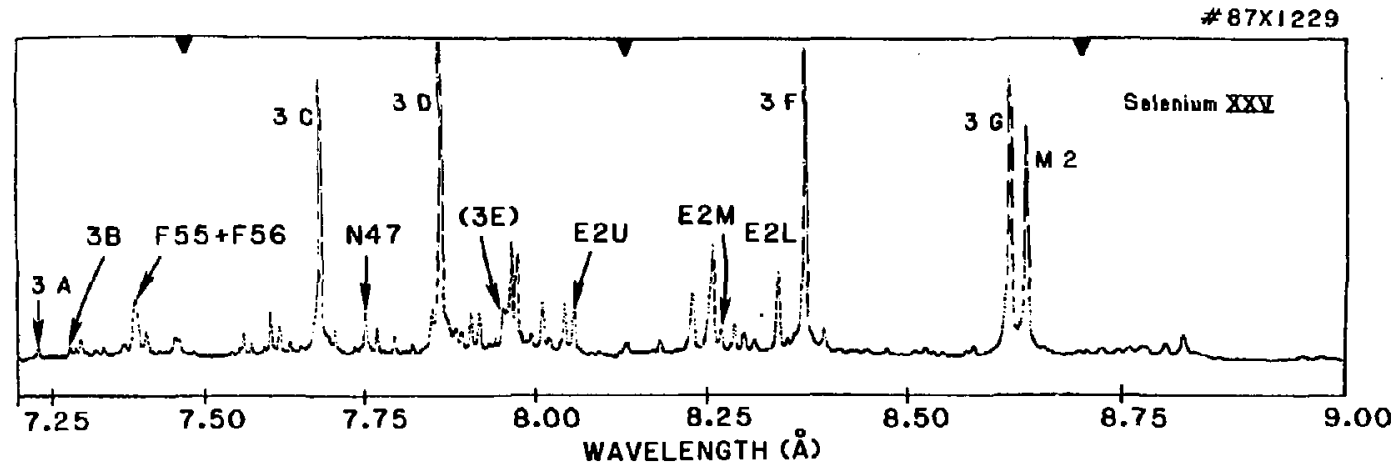

Fig. 7 


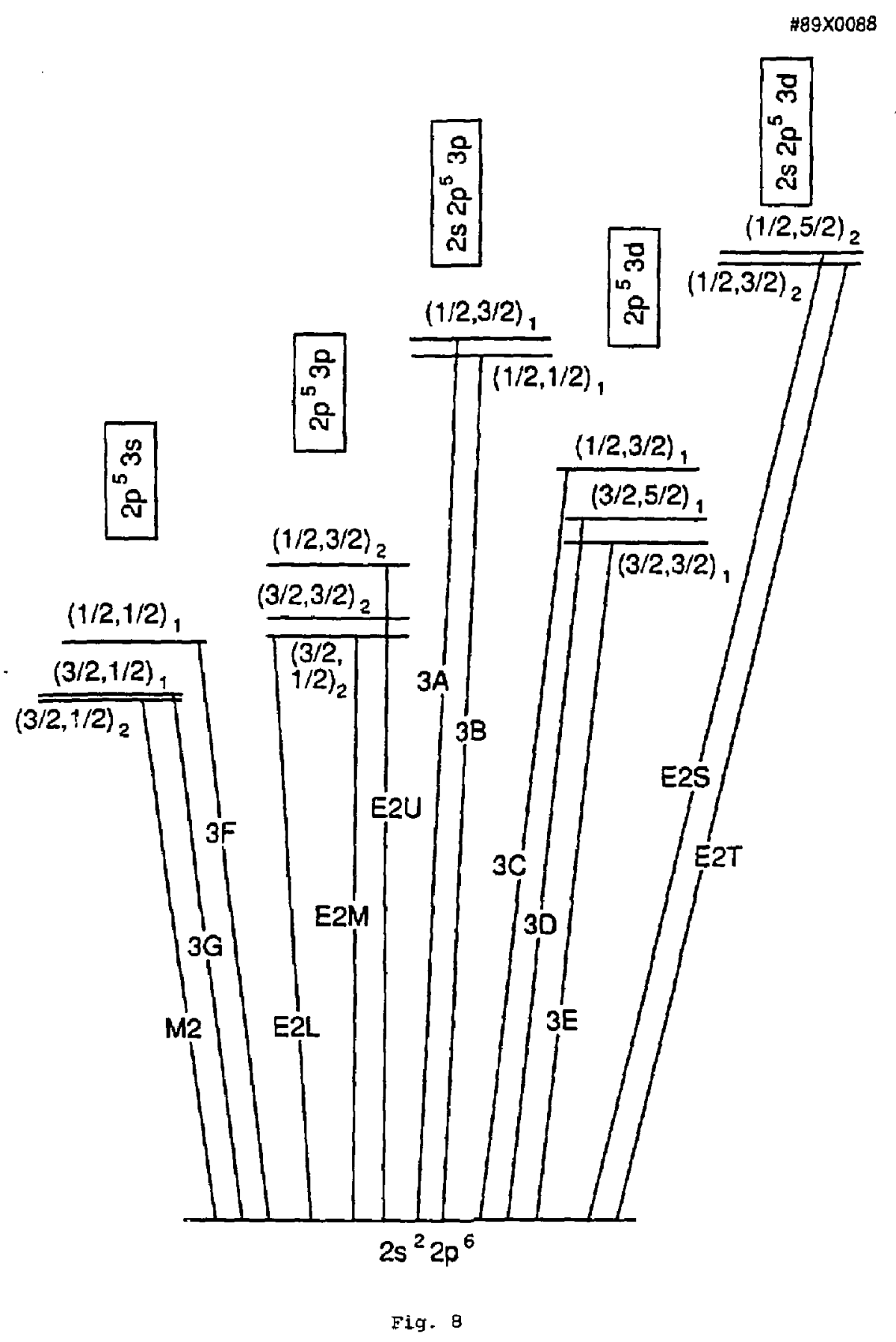




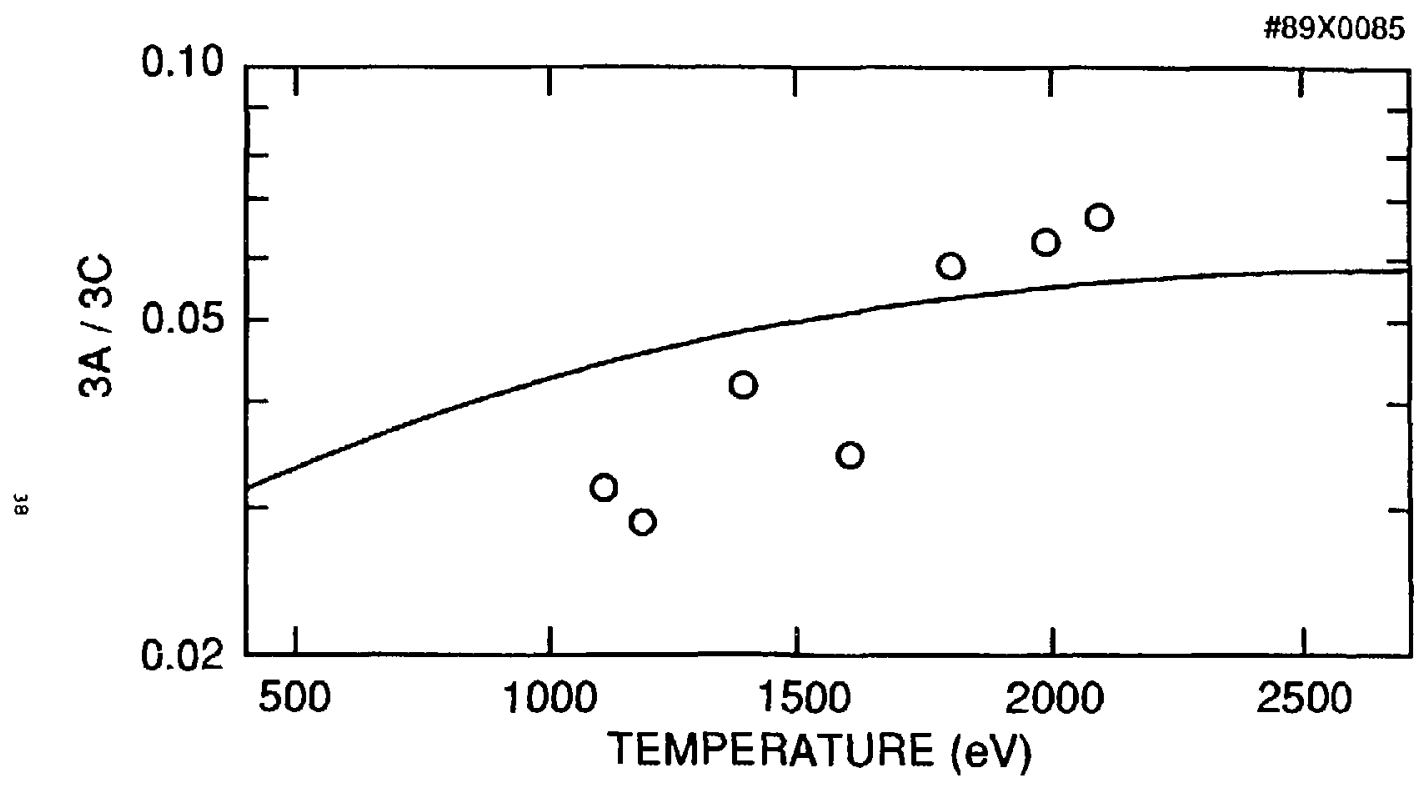

Fig. 9 


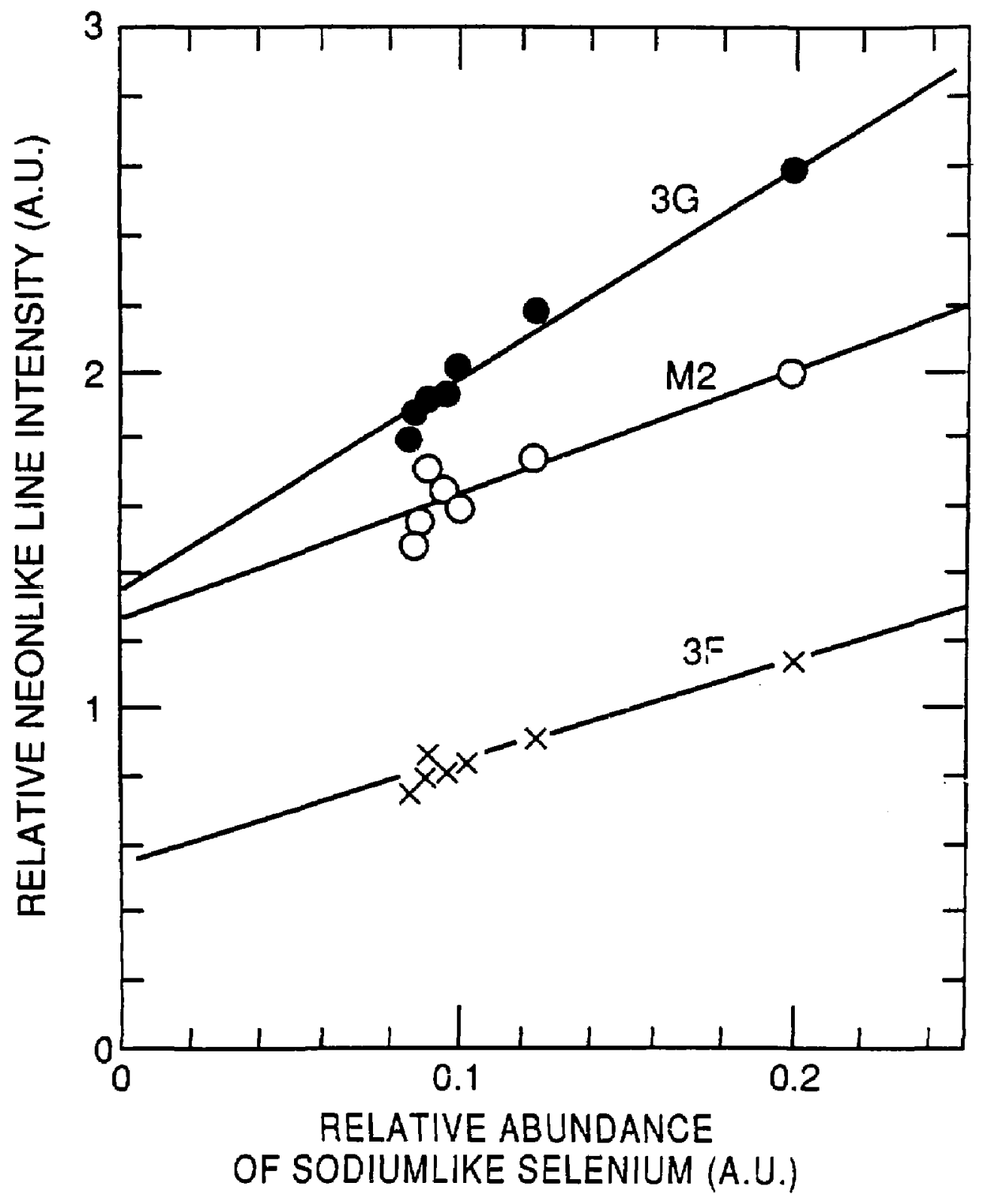

Fig. 10 


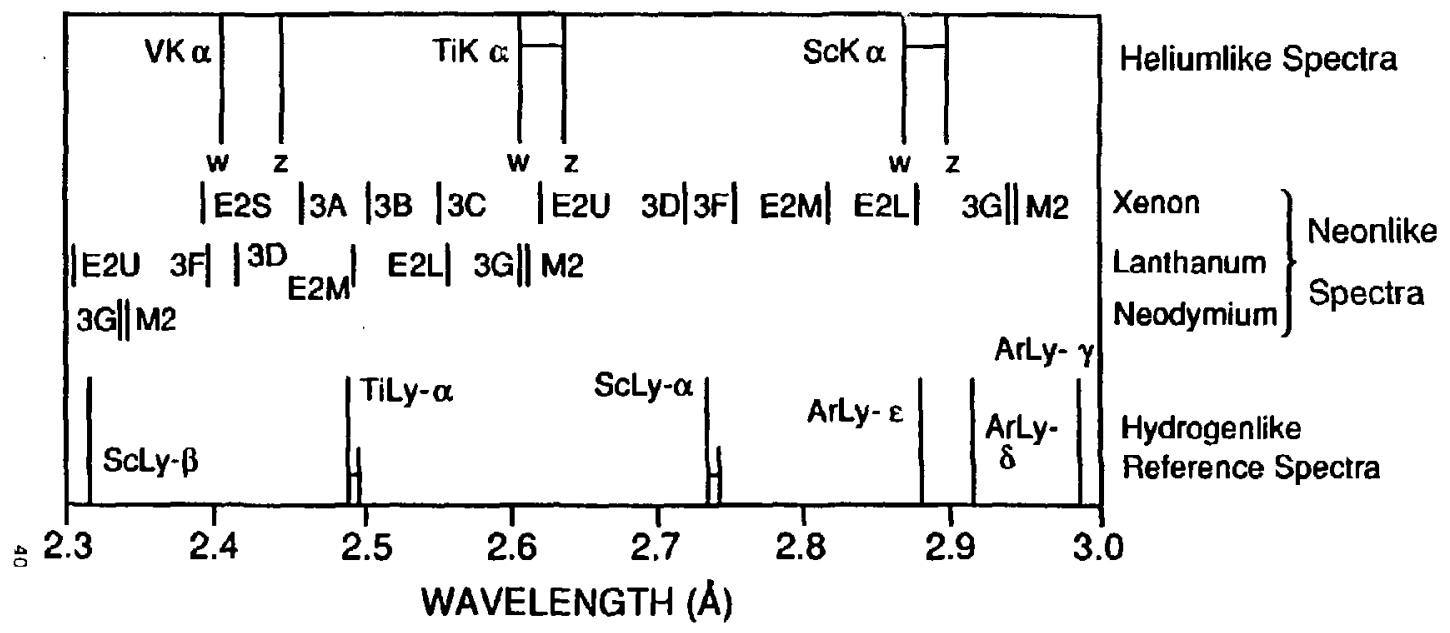

Fig. 11 


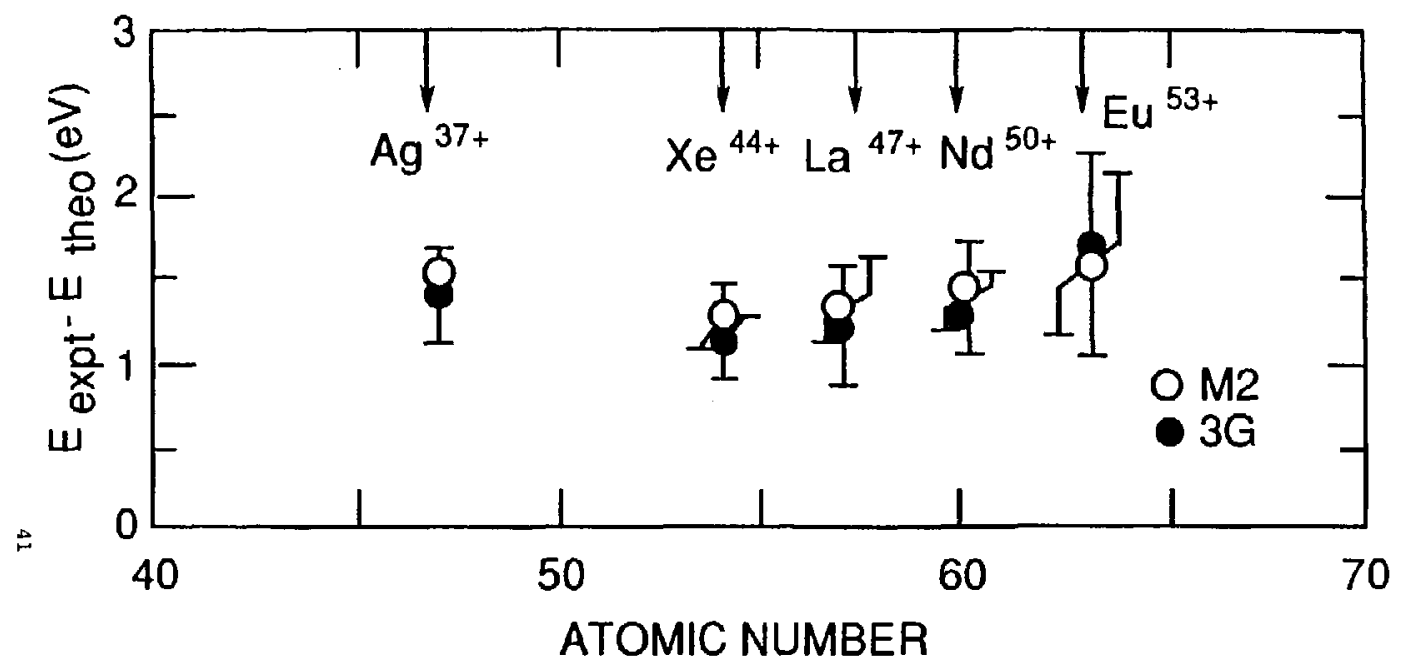

Fig. 12 

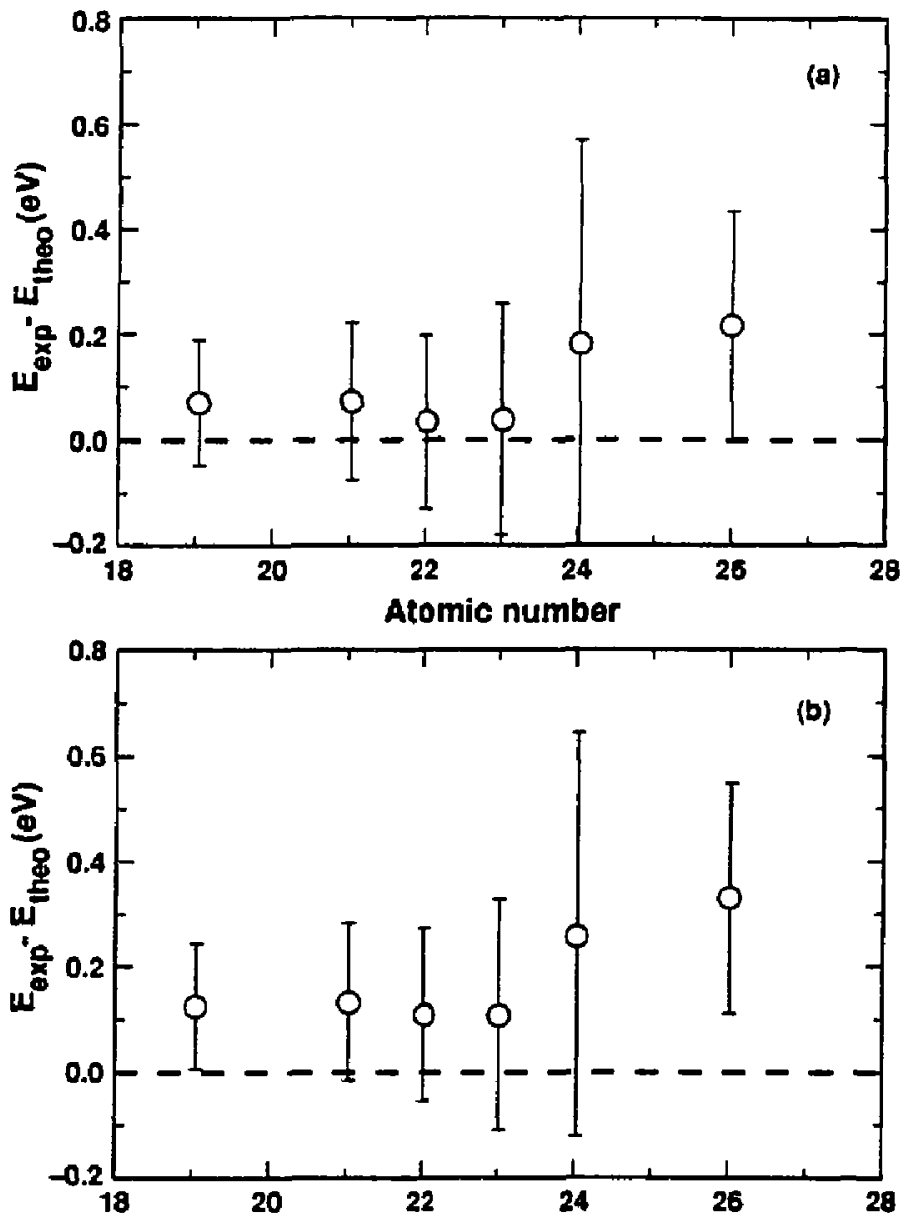

Atomic number

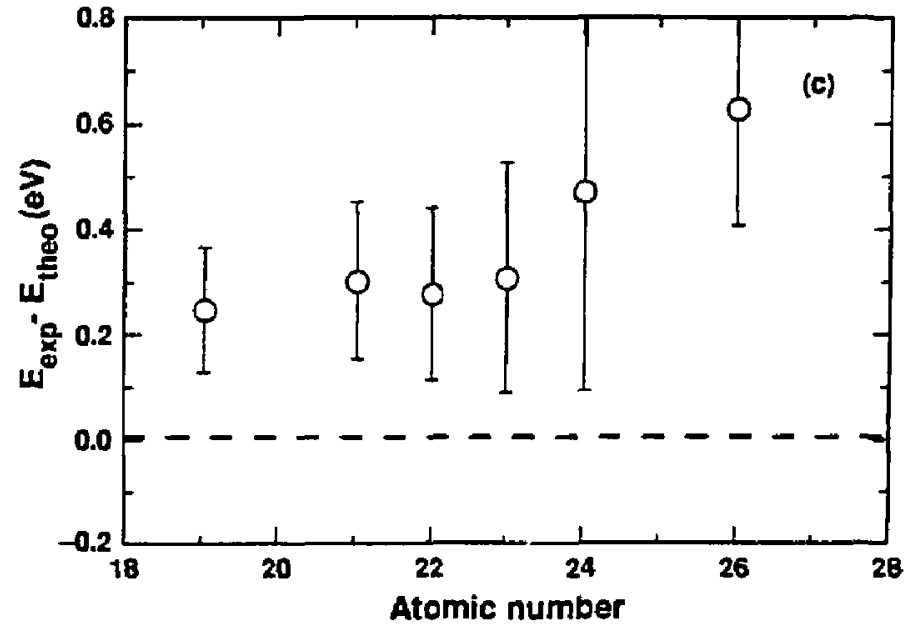


Or. Frank J. Paoloni, Univ of Hollongong, AUSTRALIA Prof. M.H. Bronnan, Univ Sydney, austahlia PI asmo Reseorch Lab., Austral ian Nat. Univ., AUSTRALIA Prot, I.A. Jones, Flinders Univ., AuSTRALIA Prof. F, Cad. Inst Theo Phys, AUSTRIA

Prot. M. Hoindler, Instut tur Theoretischo Physik, AUSTRIA M. Coossens, Astronomisch Instituut, BELGIUA Ecole Royalo Militbire. Lab de Phys Plasmes, BELGiuM Comission-European, Dg-Xil fusion Prog, BELGIUA Prot. R. Boucique, Rijksuniversiteit Gent, gELGIUH Dr. P.H. Sakanaka, Instituto Fisica, BRAZIL Instituto De Pasquises Espaciasi-INPE, BRAzIL Documents Office, Atomic Energy of Canads Limited, CANADA Dr. M.P. Bachynski, MPa Technologies, Inc, , CAHADA Dr. H.M. Skarsgard, University of Saskatchewan, CANADA Dr. H. Barnard, Univarsity of Eritish Columbia, CanadA Prof. J. Teichmonn, Univ. of Montreal, CaMuda Prof, S,R, Sreanivasan, University of Calgary, CanADA Prof. Tudor H. Johnston, INRS-Energie, CANADA Or. Bolton. Contre canadien de fusion nagnétique, Carada Dr. C.R. James, Univ, of Alberta, CANADA Dr. Peter Lukac, Komenskeho Uniy, CzECHoslovakIA The Librorian, Culha Laboratory, ENGLAND The Librarion, Rutherford Appleton Laboratory, ENGLAND Mrs. S.A. Huteninson, JET Library, EMGLAND C. Mouttet, Lao. de Ptysique des Mil ieun lonisés, france J. Radet, CEN/CADARACHE - Bat 506, FRANCE M5. C. Rinni, Librarian, Univ. of loannina, GREECE Or. Tor Mual, Academy Blbliggraphic Ser., MOnG KONG Preprint Liorary. Hungarian Acadeny of Sciences, HUNGARY Dr. B. Das Gupta, Saha Inst of Nucl. Phys., INDIA Dr. P. Kaw, institute for Plasmo Research, INDIA Dr. Philip Rosenas, Israel Inst, of Tech, ISRAEL Librarian, Int'I Ctr Theo Phys, ITALY Prof. G. Rostagni, Istituto Gas Ionizzati Del CNR, ITALY Miss Clelia De Palo, Assor: EURATCM-ENEA, ITALY Or. G. Grosso, Istituto di Fisica del Plasma, ITALY Or. H. "Jarto, Toshiba Res \& Dev, JAPAN
Prot. I. Kawakami, Atomic Energy Res. Institute, JAPAN Prof. Kyoji Nishikawd, Uniy of Hiroshima, JAPAN Director, Dept. Large Tokanak Res. JAERJ, JAPAN Prof. Sotoshi Itoh, Kyushu University, JAPAN Research Into Center, Nagova University, JAPAN Prof. S. Tonaka, Kyoto University, JAPAN Library, Kyoto University, JAPAN

Prot. Nobuyuki Inoue, University of Tokyo, JAPAN S. MOF $i$, JAERI, JAPAN

H. Joong, Librarian, Korea Advanced Energy Ros Inst, KOREA Prof. D.I. Choi, The Korea Adv. Inst of Sci \& Tecn, KOREA Prof. B.S. Li IoY, University of Waikato, MEl ZEALAND Institute of Plasma Physics, PEOPLE'S REPUBL IC OF CHINA Librarian, Institute of Phys,. PEOPLE's REPUBLIC OF CHINA Library, Tsing Hua University, PEOPLE'S REPUBLIC OF CHINA 2. Li, Southwest Inst, Physics, PEOPLE'S REPUELIC OF CHINA Prot. J.A.C. Cabral, Inst Suderior Tecnico, PORTugaz Or. Octavian Potrus, al I CuZa University. Ronania Or. Jar de Villiers, Fusion Studies, AEC, SO AFPICA Prof. M, A. Hellberg, University of Natal, SO AfRICA C.I.E.M.A.T. Fusion Div. Library. SPhIN Dr. Lennart Stentlo, University of UHEA, SHEDEN Librory, Roval institute of Tech, SWEDEN Prof. Hans Wilhelmson, Chalmers Univ of Tech, SWEDEN Centre Phys des PIesmes, Ecole Polytech Fed, \$WITZERLANo Bibliotheek, Fom-Inst Voor Plases-Fysica, THE NETHERLANDS Metin Durgut, Middle East Technical University, TuRkey Dr. D.D. Ryutov, Siberian Acad Sci, USSR Dr. G.A. El iseev. Kurchatoy Institute, USSR Dr. V.A. Glukhikh, Inst Electrophysical Apparatus, USSR Prot. 0.S. Padichenko, Inst, of Phys, \& Tech, USSR Dr. L.M. Kovriznnykn, Institute of Gen. Physics, USSR Nuclear Res. Establishment, Julich Ltd., W. Germany Bioliathek, Inst. Fur Plasmatorschung, W, GERMAkY Dr, K. Schindler, Ruhr-Universitat Bochum, W. GERMANY ASDEX Reading Rn, cro Hagner, IPPAMax-PIanck, W. GERMANY Librarian, Max-PIanck Institut, W. GERMANY Prof. R.K. Janev, inst of Phys, yugoslavia 